\title{
Waste tea residue adsorption coupled with electrocoagulation for improvement of copper and nickel ions removal from simulated wastewater
}

\section{Jean Claude Nizeyimana}

Northeast Normal University

Shanshan Lin ( $\square$ linss071@nenu.edu.cn)

Northeast Normal University, China https://orcid.org/0000-0003-2752-5328

Junaid Khan

Northeast Normal University

Wu Yifeng

Northeast Normal University

Han dongxu

Northeast Normal University

Liu Xiangru

Northeast Normal University

\section{Research Article}

Keywords: Heavy metals, green waste tea residue, iron electrode, ADS coupled EC, operating cost, Environmental remediation

Posted Date: August 23rd, 2021

DOl: https://doi.org/10.21203/rs.3.rs-746126/v1

License: (c) (i) This work is licensed under a Creative Commons Attribution 4.0 International License. Read Full License 
2 Waste tea residue adsorption coupled with electrocoagulation for 3 improvement of copper and nickel ions removal from simulated 4 wastewater

5

6 Nizeyimana Jean Claude ${ }^{\mathrm{a}}$, Lin Shanshan ${ }^{\mathrm{a}, *}$, Junaid Khan ${ }^{\mathrm{a}}$, Wu Yifeng ${ }^{\mathrm{a}}$, Han dongxu ${ }^{\mathrm{a}}$ and Liu $7 \quad$ Xiangru $^{\mathrm{a}}$

8

$9 \quad *$ Corresponding author (Lin Shanshan)

10 E-mail: $\underline{\text { linss071@ @enu.edu.cn }}$

11 Phone number: +8613321583738

12 Mailing address: School of Environment Northeast Normal University, Changchun, 130117, 13 China. 


\section{Affiliation of the authors}

15

16 Nizeyimana Jean Claude ${ }^{a}$, Lin Shanshan ${ }^{a}$,*, Junaid Khan ${ }^{\text {a }}$, Wu Yifenga ${ }^{\text {, Han }}$ dongxu ${ }^{\mathrm{a}}$ and 17 Liu Xiangru ${ }^{\mathrm{a}}$

18

19 Mailing address:

20 aSchool of Environment Northeast Normal University, Changchun, 130117, China.

21

22 E-mails: nizeyeclaude570@gmail.com (J. C. Nizeyimana), linss071@nenu.edu.cn (L. Shanshan)

23 zhundh436@nenu.edu.cn (J.Khan), 15604806169@163.com (W. Yifeng), 1986507164@qq.com

24 (H. Dongxu) and liuxr881@ nenu.edu.cn (L. Xiangru). 


\section{Author contributions}

28 Altogether authors contributed to the study conception and design

29

30 Conceptualization and writing - original draft preparation: [Jean Claude Nizeyimana]

31 Supervision and Resources: [Shanshan Lin]

32 Formal analysis and investigation: [Junaid Khan, [Wu Yifeng]

33 Writing - review and editing: [Shanshan Lin] and

34 Data collection: [Jean Claude Nizeyimana], [Junaid Khan], [Liu Xiangru] and [Han dongxu]

35

36 All authors read and approved the final manuscript.

37 


\section{Abstract}

The present research deals with the removal of copper and nickel ions from synthesized wastewater by using simple, cheap, cost-effective and sustainable activated green waste tea residue (AGWTR) adsorption coupled with electrocoagulation (ADS/EC) process in presence of iron electrode. Considering previous studies, their adsorbents used for treating their wastewaters firstly activate them by applying either chemicals or activating agents. Our adsorbent was prepared without applying neither chemicals nor any activating agents. The operating parameters of both metals were optimized: $\mathrm{pH}$ (4.0), hydraulic retention time (HRT=30 min), adsorbent dose (1 mg.L $\mathrm{L}^{-}$ $\left.{ }^{1}\right)$, initial concentration $\left(20 \mathrm{mg} \cdot \mathrm{L}^{-1}\right)$ and $\mathrm{Fe}-\mathrm{Fe}$ electrode was found to be better with compared to the other electrodes with a current density of $1.19 \mathrm{~mA} / \mathrm{cm}^{2}$. In the process of ADS/EC, The removal efficiency was obtained as $100 \%$ for copper and $99.99 \%$ for nickel ions. After the ADS/EC process, Fourier transform infrared (FT-IR) spectroscopy, Scanning Electron Microscopy (SEM) and EDS analysis were used to characterize the adsorbent green waste tea residue. The results showed seven clear peaks of functional groups that were detected in the range 66

Keywords: Heavy metals; green waste tea residue; iron electrode; ADS coupled EC; operating

of $1000-4000 \mathrm{~cm}^{-1}$, the rough-stone-like with various larger holes and higher amounts of carbon containing traces of different elements, respectively. The adsorption isotherm and kinetic model results showed that the Langmuir and the pseudo-second-order were well-fitted to the adsorption experimental data better than the Freundlich and pseudo-first-order models for both $\mathrm{Cu}^{2+}$ and $\mathrm{Ni}^{2+}$ with their maximum adsorption capacity of 15.6 and $15.9 \mathrm{mg} \cdot \mathrm{g}^{-1}$, respectively. These indicate that the dominant adsorption occurs in a monolayer of homogeneous adsorbent surfaces on AGWTR and its kinetic mechanism belongs to chemical adsorption. Based on the above results, it is well understood that the use of the ADS coupled with EC technique is the cheapest compared with single ADS and EC technique for heavy metal removal due to remarkable low adsorption dose, energy consumption and also it is a suitable technique for developind countries. Therefore, the AGWTR shows the greatest potential to improve the quality of water contaminated with different heavy metals in the environment. cost; Environmental remediation 


\section{Introduction}

People have begun to realize how essential excellent health is to them, and it is no longer merely important to have a standard lifestyle for mankind. Because there is a direct relationship between environment, health, and population, it is importantly to have a stable environment if we want to live a healthy life. Every day, the world's population grows, and this influences the ecosystem. The amount of water used increases as the population rises, which has a direct effect on the water bodies and it has aggravated the issue of water (Jayasinghe, Riswan, and Ishaq 2021). The demand for products and services develops in tandem with the population. As the population expands, so do the demands on resources. Increased demand leads to the development of new industries and resources. As a result of increased industrialisation, heavy metal poisoning in water sources and its severe health effects on human society are becoming a major problem (Si et al. 2015). Because heavy metals are resistant to degradation and bioaccumulation in living and nonliving organisms, people in many nations are exposed to them through contaminated water. Heavy metals such as copper and nickel, as an example, have a negative impact on environmental sources (Ali and Ateeg 2015). common metal in the environment, although little is known about its practical applications for are common as a result of coming into touch with nickel-containing objects, and the carcinogenic effects of $\mathrm{Ni}^{2+}$ are well recognized (Genchi et al. 2020). Pollution of $\mathrm{Cu}^{2+}$ is caused by, manning activities, electroplating, and smelting, as well as the utilised of copper-based agrichemicals and manufacturing of brass. Copper is the most toxic metal to animals, and long-term inhalation of $\mathrm{Cu}-$ containing sprays has been linked to an increased risk of lung cancer in those who have been exposed (Santos et al. 2020). At low levels, copper can play a significant role in human and animal metabolism. Too much copper, on the other hand, can cause serious side effects and toxicological concerns like convulsions, vomiting, cramps, and even death (Paulino et al. 2006). Nickel is a humans and animals. Municipal and industrial waste, as well as the usage of liquid and solid fuels, all contribute to nickel pollution. Nasal cancer, contact dermatitis, headaches, allergies, lung fibrosis, cardiovascular and kidney damage, and other toxicological concerns are all caused by it (Genchi et al. 2020). The World Health Organization (WHO) estimates the maximum permitted concentrations of $\mathrm{Cu}^{2+}$ and $\mathrm{Ni}^{2+}$ in drinking water to be less than $2 \mathrm{mg} . \mathrm{L}^{-1}$ and $0.02 \mathrm{mg} . \mathrm{L}^{-1}$, 
respectively (Ahuja, Singh, and Singh 2019). As a result, removing both metals from polluted water is critical. Heavy metal removal from contaminated water is currently done in different of techniques including anaerobic biological treatment (Watari et al. 2021), sonolysis (Watari et al. 2021), and photocatalytic and oxidation destruction via Ultraviolet/ozone treatment (Goodarzvand Chegini et al. 2020), flocculation and coagulation (Lapointe et al. 2020), adsorption (Liakos et al. 2021), biodegradation (Imron, Kurniawan, and Titah 2019) and electrocoagulation (Syaichurrozi et al. 2021), etc. However, these methods have several drawbacks, including limited removal efficiency, high running costs, and the production of a lot of sludge, which is not environmentally friendly. Thus, to reduce potential pollution, high operating costs, and low efficiency; the best answer to this problem is to combine two or more efficient techniques. In this study, the integration of adsorption (ADS) and electrocoagulation (EC) methods are suggested as an interesting alternative method to treat polluted water and wastewater.

Heavy metal ions can be eliminated from contaminated water by means of adsorption process, which has been demonstrated to be effective. Due to its efficiency and low cost, ADS has been recommended as a technology for removing $\mathrm{Cu}$ and $\mathrm{Ni}$ metals from water and wastewater. It does not produce secondary sludge (Sikdar, Goswami, and Das 2020). Adsorbents such as lignocellulosic biomasses (Narendrakumar and Senthil 2020), fly ash (Buema et al. 2021), powdered marble wastes (Mehta, Mondal, and George 2016), activated carbon (Rahimian and Zarinabadi 2020), clays and biochars (Yao et al. 2014) have all been used to remove contaminants including metal ions in adsorption method. All of the adsorbents discussed above have some drawbacks, such as low efficiency, high cost, and limited availability. As a result, we have developed activated green waste tea residue (AGWTR) as a long-term, low-cost, and more effective adsorbent. It is easily accessible on a huge scale throughout the world. No activating chemicals, coatings, or modifications were used to activate our material (AGWTR). In this work, we chose AGWTR to decrease the barriers associated with dangerous chemicals, high costeffective and lengthier preparation processes to obtain the best removal efficiency of heavy metal treatment through the use of an environmentally benign and sustainable adsorbent. This is the key research topic, and it involves activation, which has a high adsorption capacity (Deng et al. 2021).

The electrocoagulation process needs simultaneous metal dissolution from the anode electrode and hydrogen gas and hydroxyl ions production at the cathode electrode. All 
contaminants that can be eliminated by electrocoagulation include total organic carbon, heavy metals (Ilhan et al. 2019a), antibiotics and medicines (Pandiarajan, Kamaraj, and Vasudevan 2017), and organic pollutants such herbicides, phenols, and textile dyes (Aravind et al. 2016). A sacrificial metal anode and a cathode are the two electrodes in an electrochemical cell. The anodes in our study were iron $(\mathrm{Fe})$ electrodes. The EC creates iron ions from a sacrificial anode, which hydrolyze in water and produce a variety of coagulant species. Coagulation is the process of combining these coagulant species to generate bigger particles (Moussa et al. 2017). Coagulation is a process that uses coagulant chemicals to destabilize particles and allow them to bind to other particles. Iron salts were hydrolyzed in water to produce insoluble precipitates, which then adsorb on the surface of the particles, destabilizing their charge. Because the particles have identical electric charges, which are usually negative, there are repulsive interactions between them. (Myllymäki et al. 2018) found that the hydrolyzed products had a positive electric charge. On the surface of the cathode, electrolytically created gases, primarily hydrogen, are produced. Gas bubbles are produced as a result of favorable side reactions, which aid in floating. These agglomerated pollutants form more agglomerates, which push higher and are destroyed in the next step. On the cathode, a final electrochemical reaction called reduction may occur (Ilhan et al. 2019a). The electrochemical dissolution of the iron anode is much more complex because there are two oxidation states of iron species: $\mathrm{Fe}^{2+}$ and $\mathrm{Fe}^{3+}$ (Eq.1). According to solution $\mathrm{pH}$ and the dissolved oxygen, $\mathrm{Fe}^{2+}$ species can be potentially oxidized to the $\mathrm{Fe}^{3+}$ (Eq.2) and finally, hydrolyzed to form the hydroxide (Eq.3) (Panizza and Cerisola 2010).

$\mathrm{Fe}_{(\mathrm{s})} \longrightarrow \mathrm{Fe}^{2+}(\mathrm{aq})+2 \mathrm{e}^{-}$

$4 \mathrm{Fe}^{2+}{ }_{(\mathrm{aq})}+\mathrm{O}_{2}+4 \mathrm{H}^{+} \longrightarrow 4 \mathrm{Fe}^{3+}(\mathrm{aq})+2 \mathrm{H}_{2} \mathrm{O}$

$\mathrm{Fe}^{3+}(\mathrm{aq})+3 \mathrm{H}_{2} \mathrm{O} \longrightarrow \mathrm{Fe}(\mathrm{OH})_{3}+3 \mathrm{H}^{+}$

The main reaction at the cathode is hydrogen evolution (Eq.4):

$$
2 \mathrm{H}_{2} \mathrm{O}+2^{\mathrm{e}-} \longrightarrow \mathrm{H}_{2}+2 \mathrm{OH}^{-}{ }_{(\mathrm{aq})}
$$

Based on the above discussions, we have chosen the combination of adsorption with electrocoagulation (ADS/EC) process as the most favorable methodology for wastewater treatment due to its simplest, less expensive, require low electricity and giving superior and optimistic results 
155 156

compared with adsorption or electrocoagulation method alone. It offers the following advantages: (i) simplicity of operation, (ii) rapid sedimentation, (iii) low sludge production and (iv) environmental compatibility.

The objective of this study is to remove $\mathrm{Cu}^{2+}$ and $\mathrm{Ni}^{2+}$ from synthesized wastewater by using the combination of the activated green waste tea residue adsorption without applying any chemical reagents with electrocoagulation techniques in presence of iron electrode at the lowest possible cost. No other published works were dealing with the combination of adsorption using natural green tea waste residue and iron electrocoagulation techniques for removing $\mathrm{Cu}^{2+}$ and $\mathrm{Ni}^{2+}$ from wastewater. The comparison of ADS and EC integration for both single and binary systems, as well as the total operating cost, was investigated in this paper. The effects of $\mathrm{pH}$, treatment time, adsorbent dose, initial concentration and current density on removal efficiency were studied in this study. Adsorption isotherms (Langmuir and Freundlich) and the kinetic modeling (pseudo-firstorder, pseudo-second-order) of $\mathrm{Cu}^{2+}$ and $\mathrm{Ni}^{2+}$ were discussed. This material was chosen because of its inexpensive cost and wide availability around the world, particularly in developing countries.

\section{Experimental section}

\subsection{Materials}

Green waste tea residue (GWTR) was purchased from Pinduoduo Inc., China. The AGWTR was produced using the physical activation processes. This activated carbon was derived from crushed GWTR biomass and then sieved, resulting in a fine adsorbent with a particle size of $0.45 \mu \mathrm{m}$ (mesh size) and finally heated at $500^{\circ} \mathrm{C}$ in 2 hours. Synthesized wastewater was prepared from stock solutions of $1000 \mathrm{mg} / \mathrm{L} \mathrm{Cu}^{2+}$ ion obtained from copper chloride dihydrate $\left(\mathrm{CuCl}_{2} \cdot 2 \mathrm{H}_{2} \mathrm{O}\right)$ and $\mathrm{Ni}^{2+}$ ion obtained from nickel chloride hexahydrate $\left(\mathrm{NiCl}_{2} \cdot 6 \mathrm{H}_{2} \mathrm{O}\right)$. The solution of $0.1 \mathrm{M}$ sodium hydroxide $(\mathrm{NaOH})$ and hydrochloric acid $(\mathrm{HCl})$ was used for $\mathrm{pH}$ adjustment and cleaning some materials. Iron electrodes bought from Taobao Inc., and DC power supply (Maisheng MS605D) also were used during the electrocoagulation process. During the experiment, double distilled and deionized water were utilized. 


\subsection{Experimental setup}

The lab-scale batch experimental setup was used in combining the ADS/EC studies schematically shown in Fig.1. The EC cell was constructed from a thick glass container with dimensions of $20 \mathrm{~cm} \times 10 \mathrm{~cm} \times 0.5 \mathrm{~cm}$ in length, width, and height, respectively. Copper and nickel solutions were agitated at $150 \mathrm{rpm}$ (Agitator: Lichen DF-101Z) and the temperature was kept constant at $25 \pm 1^{\circ} \mathrm{C}$. The AGWTR was mixed with synthesized wastewater at various dosages (0.1-5 g.L $\left.\mathrm{L}^{-1}\right)$ in the combined system. The synthesized wastewater volume used in the experiment was 3L. Iron (Fe-Fe) electrodes of $12 \mathrm{~cm}$ high, $7 \mathrm{~cm}$ wide and $0.2 \mathrm{~cm}$ in thickness were utilized for the sacrificial electrodes where Fe-Fe were used for both anode and cathode and also they were arranged in a monopolar configuration. The distance between electrodes was $1 \mathrm{~cm}$. A peristaltic pump was used also in this experiment. The submerged surface area of electrodes was $84 \mathrm{~cm}^{2}$ and two plates were constructed in the electrochemical reactor. The ADS process in presence of AGWTR-reaction occurred from the bottom of the reactor while in the EC process, the electrodesreaction happened at both the bottom and the top of the reactor. We were using a DC power source with a current of $0-5 \mathrm{~A}$ and a voltage of $0-30 \mathrm{~V}$, a continuous direct current was maintained for supplying current density.

\subsection{Preparation of the adsorbent}

To begin, GWTR was thoroughly cleaned with distilled water to remove any adherent particles, and then dried in a hot air oven at $100^{\circ} \mathrm{C}$ for 2 hours. Then the dried biomass was crushed by using a crushing machine and sieved to get a fine adsorbent with a fine particle size of $0.45 \mu \mathrm{m}$ (mesh). Finally, sieved GWTR was placed inside the muffle furnace for heating it at $500{ }^{\circ} \mathrm{C}$ for 45 minutes in presence of $\mathrm{N}_{2}$ atmosphere for converting the green waste tea residue into activated carbon (biochar). After completion of the process, the activated green waste tea residue (AGWTR) was taken out and cooled for 5 hours and stored in a plastic rubber for further experiment.

\subsection{Preparation of electrodes}

Iron $(\mathrm{Fe}-\mathrm{Fe})$ plates of $12 \mathrm{~cm} \times 7 \mathrm{~cm} \times 0.2 \mathrm{~cm}$ dimension were utilized as electrodes in both anodes and cathode. The iron electrodes were washed in $0.1 \mathrm{M} \mathrm{HCl}$ to remove rust and other 
$q_{e}=\frac{V}{m}\left(C_{0}-C_{\mathrm{e}}\right)$

234

$\% R=\frac{C_{0}-C_{\mathrm{e}}}{C_{0}} \times 100$ and $\mathrm{Ni}^{2+}$ was given by:

attached particles, then cleaned using a brush and distilled water before being dried in a dry oven at $70^{\circ} \mathrm{C}$ for 10 minutes before it was used.

\subsection{Batch Adsorption / electrocoagulation coupling process}

The combining experiment was studied as follow: the amounts of activated green waste tea residue (GWTR) were tested and mixed with 3L of synthesized solutions (1L of copper, 1L of nickel and 1L of mixed of both metal solutions) in different Erlenmeyer flasks, then the ADS studies were conducted in $100 \mathrm{~mL}$ and each solution had a concentration of $20 \mathrm{mg}$. $\mathrm{L}^{-1}$. The solution was stirred at $150 \mathrm{rpm}$ and ambient temperature was applied in this experiment. The sample was collected at regular time from an electrocoagulation cell and then filtered by using Whatman microfiber filter of $0.45 \mu \mathrm{m}$ pore size before being analyzed by atomic adsorption spectrophotometer (AAS Z-5000, Japan). The pH was maintained continuously by using a multiparameter instrument (SX725 pH/mV /DO meter). The characteristic of mineral composition, surface morphology and bonding patterns of a compound found in AGWTR after ADS and also compound observed in sludge after EC were evaluated by using the Fourier transform infrared (FT-IR-Magna 560) spectra, Scanning electronic microscope (SEM), and EDS analysis (JEM$2100 \mathrm{~F}, 200 \mathrm{Kv})$. To confirm the optimum level of high removal efficiency, the experiment was repeated at different levels. Effect of various parameters have been investigated during the lab experiment treatment time (10-180 min), pH (2-8), agitation speed (50-200 rpm), adsorbent dosage $(0.1-5 \mathrm{~g})$, initial concentration of $\mathrm{Cu}^{2+}$ and $\mathrm{Ni}^{2+}\left(20-120 \mathrm{mg}^{2} \mathrm{~L}^{-1}\right)$, Temperature $\left(20-40{ }^{\circ} \mathrm{C}\right)$, current density $\left(0.11-2.5 \mathrm{~mA} / \mathrm{cm}^{2}\right)$ and total operating cost. The percentage of copper and nickel ions removal was calculated from the following equation (5):

The mass balance equation was used to calculate equilibrium concentration, $\mathrm{q}_{\mathrm{e}}\left(\mathrm{mg} \cdot \mathrm{g}^{-1}\right) \mathrm{of} \mathrm{Cu}^{2+}$

Where $C_{0}$ and $C_{e}$ are the initial and equilibrium concentration of $\mathrm{Cu}^{2+}$ and $\mathrm{Ni}^{2+}$ in $\mathrm{mg} . \mathrm{L}^{-1}, \mathrm{~m}$ is the amount of AGWTR (g) and V (L) is the volume of solution. 


$$
R_{L}=\frac{1}{1+K_{L} C_{O}}
$$

258 where, $\mathrm{C}_{\mathrm{o}}$ is the initial concentration of metal ion $\left(\mathrm{mg} \cdot \mathrm{L}^{-1}\right), \mathrm{K}_{\mathrm{L}}$ : Langmuir isotherm constant). $\mathrm{R}_{\mathrm{L}}$ 259 value indicates the adsorption nature either unfavorable $\left(R_{L}>1\right)$, linear $\left(R_{L}=1\right)$, favorable $\left(0<R_{L}<1\right)$ 260 and irreversible $\left(\mathrm{R}_{\mathrm{L}}=0\right)$. 
261 Freundlich isotherm model is commonly applied to describe the process of adsorption features of

262 the heterogeneous surface. The linear equation of Freundlich isotherm is expressed below:

$263 \quad \ln q_{e}=\frac{1}{n} \ln C_{e}+\ln K_{F}$

264 where $\mathrm{K}_{\mathrm{f}}$ is Freundlich isotherm constant $\left(\mathrm{mg} \cdot \mathrm{g}^{-1}\right)$, $\mathrm{q}_{\mathrm{e}}$ : the amount of adsorbed metal gram of the 265 adsorbent at equilibrium $\left(\mathrm{mg} \cdot \mathrm{g}^{-1}\right), \mathrm{C}_{\mathrm{e}}$ : the equilibrium concentration of adsorbate (mg.L $\left.\mathrm{L}^{-1}\right)$ and $\mathrm{n}$ : 266 adsorption density.

\subsection{Adsorption Kinetic modeling}

To study kinetics took part in the removal of metal ions from a solution and the degree of adsorption was calculated as a function of time. In this study, the concentration of $\mathrm{Cu}^{2+}$ and $\mathrm{Ni}^{2+}$

270 at time $\mathrm{t}, \mathrm{q}_{\mathrm{t}}\left(\mathrm{mg} \cdot \mathrm{g}^{-1}\right)$ was computed. The kinetic data were examined by using pseudo-first-order 271 and pseudo-second-order models. The pseudo-first-order kinetic model was developed and 272 expressed as follows:

$273 \ln \left(q_{e}-q_{t}\right)=\ln q_{e}-K_{1} t$

274 where, $\mathrm{q}_{\mathrm{t}}$ : the amount of adsorbed metal ion per gram of adsorbent at any time (mg. $\mathrm{g}^{-1}$ ), $\mathrm{q}_{\mathrm{e}}$ : the 275 amount of metal ions adsorbed per gram of adsorbent at equilibrium $\left(\mathrm{mg}^{-\mathrm{g}^{-1}}\right), \mathrm{K}_{1}=$ the adsorption 276 rate constant $\left(\mathrm{min}^{-1}\right)$ and $\mathrm{t}$ is a constant time (min). The adsorption rate constant $\mathrm{K}_{1}$ was computed 277 from the slope of the graph drawn $\ln \left(q_{e}-q_{t}\right)$ against $\mathrm{t}$ and the theoretical $q_{e}$ was computed from 278 the breaking point on the graph.

279 While the pseudo second-order kinetic model was developed and expressed as follows:

$280 \frac{1}{q_{t}}=\frac{1}{K_{2} q_{e}^{2}}+\frac{t}{q_{t}}$

281 where, $\mathrm{q}_{\mathrm{t}}$ : the amount of adsorbed metal ion per gram of adsorbent at any time (mg/g), $\mathrm{q}_{\mathrm{e}}$ : the 282 amount of metal ions adsorbed per gram of adsorbent at equilibrium $(\mathrm{mg} / \mathrm{g}), \mathrm{K}_{2}=$ the adsorption 283 rate constant $(\mathrm{g} / \mathrm{mg} / \mathrm{min}), \mathrm{K}_{2} \mathrm{q}_{\mathrm{e}}^{2}$ is initial adsorption speed and $\mathrm{t}$ is a constant time (min). The 284 adsorption rate constant $\mathrm{K}_{2}$ and theoretical $\mathrm{q}_{\mathrm{e}}$ values are calculated respectively from the slope and 285 breakpoint of the graph drawn $t / q_{t}$ against $t$. 


\subsection{Energy consumption and amount of dissolved electrodes}

Energy consumption is a very important cost factor of the electrocoagulation treatment process. It is proportional to the electric current and applied voltage. The energy used for removing $\mathrm{Cu}^{2+}$ and $\mathrm{Ni}^{2+}$ was calculated by the following equation:

$290 \quad \mathrm{w}\left(\mathrm{kWh} \cdot \mathrm{m}^{-3}\right)=\frac{\mathrm{I} \times \mathrm{t} \times \mathrm{v}}{1000 \mathrm{~V}}$

291

292

293

294

295

296

297

298

299

300

301

302

303

304

305

306

307

308

309

310

311

where $\mathrm{W}$ is energy consumption $\left(\mathrm{kWh} \cdot \mathrm{m}^{-3}\right)$, I is the electric current $(\mathrm{A}), \mathrm{v}$ is applied voltage (volt), $\mathrm{t}$ is the reaction time $(\mathrm{h})$ and $\mathrm{V}$ the sample volume $\left(\mathrm{m}^{3}\right)$. Additionally, Faraday's law describes the mass of iron electrodes dissolved in the solution. It is shown as:

$m_{F e}=\frac{I \times t \times M_{w}}{Z F}$

where $\mathrm{m}_{\mathrm{Fe}}$ is the mass of dissolved iron electrode $\left(\mathrm{kg} / \mathrm{m}^{3}\right)$, $\mathrm{I}$ is the current $(\mathrm{A})$, $\mathrm{t}$ is the electrolysis time (s), $\mathrm{M}_{\mathrm{w}}$ is the molecular mass of $\mathrm{Fe}(56 \mathrm{~g} / \mathrm{g} \cdot \mathrm{mol}), \mathrm{z}$ is the number of electrons involved in the reaction Fe (2) and Faraday's constant (96,485.34 C/mol).

\section{Result and Discussion}

\subsection{Characteristic of adsorbent}

\subsubsection{Scanning Electron Microscopy (SEM) analysis and EDS analysis}

SEM was used to characterize the surface morphology of AGWTR. The SEM photographs of AGWTR before adsorption, after adsorption and after adsorption coupled with electrocoagulation of $\mathrm{Cu}^{2+}$ and $\mathrm{Ni}^{2+}$ removal are showed in Fig. (2a, b, c, d and e). The roughstone-like with various larger holes have been observed in AGWTR before ADS Fig. (2a). There are rugged holes on external surfaces like crispy pits which are visible. The rubbish surrounding those small holes causes the highest adsorption of both metals and they have been observed after adsorption of $\mathrm{Cu}^{2+}$ and $\mathrm{Ni}^{2+}$, respectively (Fig. $2 \mathrm{~b}$ and d). While Fig.2 (c) and (e) show a plane highway-like which is smooth surface untimely. This means that the rough potholes that were observed in (Fig. 2 b and d) for the AGWTR, was diminished and changed to smooth surface look like plane surface after copper and nickel adsorption coupled with electrocoagulation process, this means that $\mathrm{Cu}^{2+}$ and $\mathrm{Ni}^{2+}$ are absorbed maximally on AGWTR surface and also we confirmed that 
312 313

our material (AGWTR) showed the active site to adsorb $\mathrm{Cu}^{2+}$ and $\mathrm{Ni}^{2+}$ in maximum (Patil et al. 2019).

The EDS spectrum as observed in Fig. 2(f, g, h, I and j), showed that the AGWTR is contained the elements such as $\mathrm{C}, \mathrm{Fe}, \mathrm{O}_{2}, \mathrm{Al}, \mathrm{Si}, \mathrm{Na}, \mathrm{Cu}, \mathrm{P}, \mathrm{Cl}, \mathrm{Ni}, \mathrm{K}$ and $\mathrm{Ca}$. The percentage of elements observed in AGWTR before adsorption is $79.89 \%, 17.52 \%$ and $1.92 \%$ for carbon, oxygen and potassium, respectively and the remaining elements such as $\mathrm{Si}, \mathrm{P}, \mathrm{S}, \mathrm{Cl}, \mathrm{Al}$ and $\mathrm{Ca}$ have the percentage of $0.69 \%$ (Fig. 2f). While Fig. 2(g) and (i), showed the morphology of AGWTR after the adsorption of copper and nickel, respectively. Some changes appeared on the surface of AGWTR where we found new peaks of copper and nickel. Furthermore, the lack of a sodium peak in the EDS spectrum revealed that copper and nickel ions swapped $\mathrm{Na}^{+}$. Then, the EDS analysis of AGWTR after adsorption coupled with electrocoagulation (Fig.2h and j) mainly represented the presence of some new peak of Fe which was not observed in the first adsorption process due to the dissolution of Fe-electrode used during electrocoagulation in both copper and nickel ions removal spectrum. The images observed from SEM in this research display similar results as those published by Nikolic and Yildiz (Nikolic, Jeffry Robert, and Girish 2019; Y1ldiz, Çekim, and Dere 2017).

Figure 2. (a) SEM image of AGWTR before adsorption, (b) SEM image of AGWTR after adsorption of Cu2+, (c) SEM image of AGWTR after ADS/EC of Cu2+, (d) SEM image of AGWTR after adsorption of Ni2+, (e) SEM image of AGWTR after ADS/EC of Ni2+. (f) EDS spectra of AGWTR before adsorption, (g) EDS spectra of AGWTR after adsorption of $\mathrm{Cu}^{2+}$, (h) EDS spectra of AGWTR after ADS/EC of $\mathrm{Cu}^{2+}$,(i) EDS spectra of AGWTR after adsorption of $\mathrm{Ni}^{2+}$ and (j) EDS spectra of AGWTR after ADS/EC of $\mathrm{Ni}^{2+}$.

\subsubsection{Fourier Transform Infrared (FT-IR) analysis}

To investigate the characteristics of functional groups of activated green waste tea as another adsorbent that is responsible for the $\mathrm{Cu}^{2+}$ and $\mathrm{Ni}^{2+}$ adsorption on its surface, Fourier Transform Infrared (FT-IR) spectrum analysis was performed. Fig. 3A and Fig. 3B illustrate FTIR spectra of AGWTR before ADS (a), AGWTR after ADS (b) and AGWTR after coupling ADS/ EC (c) for both $\mathrm{Cu}^{2+}$ and $\mathrm{Ni}^{2+}$, respectively. In this research, the FT-IR spectrum of AGWTR was detected in the range of 1000-4000 $\mathrm{cm}^{-1}$. The FTIR spectrum of coupling ADS/EC for both copper and nickel absorption (c), there are seven clear peaks, the peak found at wavenumber 3736-3730 
$341 \mathrm{~cm}^{-1}$ showed a strong band of amine or hydroxyl (N-H or -OH) groups (Cherdchoo et al., 2019). 342 The band presented at $2923 \mathrm{~cm}^{-1}$ and $2852 \mathrm{~cm}^{-1}$ may be indicated to the $-\mathrm{C}-\mathrm{H}$ stretching vibration 343 from aliphatic compounds (Nigam et al. 2019). The aromatic ring vibration is observed at the sharp 344 peak of $1604 \mathrm{~cm}^{-1}$ (Ahmaruzzaman and Gayatri 2010). The absorption at $1597 \mathrm{~cm}^{-1}$ indicated N$345 \mathrm{H}$ bending in the adsorbent (Cherdchoo, Nithettham, and Charoenpanich 2019). The $\mathrm{C}=\mathrm{N}$ stretching in heterocyclic rings was also identified at wavenumber $1437 \mathrm{~cm}^{-1}$ while the peak appearing at $1373 \mathrm{~cm}^{-1}$ showed the deformation vibration of $-\mathrm{C}-\mathrm{H}$ groups of alkanes (Uzun et al. 2010). The peak at $1316 \mathrm{~cm}^{-1}$ is due to the $\mathrm{C}-\mathrm{OH}$ stretching vibration of alcohols and finally, the carboxylic acids were observed at peak $1156 \mathrm{~cm}^{-1}$ of the AGWT. By analyzing the relationship between these metal ions $\left(\mathrm{Cu}^{2+}\right.$ and $\left.\mathrm{Ni}^{2+}\right)$ removal, we observed that AGWTR shows almost similar functional groups which are responsible for the $\mathrm{Cu}^{2+}$ and $\mathrm{Ni}^{2+}$ adsorption on its surface. But some little differences have been observed on both metal peaks of $1604 \mathrm{~cm}^{-1}$ and $1156 \mathrm{~cm}^{-1}$ found in $\mathrm{Ni}^{2+}$ and $\mathrm{Cu}^{2+}$ removal, due to interaction between $\mathrm{Ni}^{2+}$ and carbon aromatic structures and interaction between $\mathrm{Cu}^{2+}$ the carboxylic acid groups, respectively on the surface of AGWTR.

355 Therefore, it can be well-known that activated green waste tea would be capable of $\mathrm{Cu}^{2+}$ and $\mathrm{Ni}^{2+}$ removal.

Figure 3. FT-IR spectroscopy characterization of activated green waste tea: A(a) AGWTR before adsorption, (b) AGWTR after adsorption of Cu2+ and (c) AGWTR after ADS/EC of Cu2+. B (a) AGWTR before adsorption, (b) AGWTR after adsorption of Ni2+ and (c) AGWTR after ADS/EC of $\mathrm{Cu}^{2+}$. B (a) AGWTR before adsorption, (b) AGWTR after adsorption of $\mathrm{Ni}^{2+}$ and (c) AGWTR after ADS/EC of $\mathrm{Ni}^{2+}$.

\subsection{Effect of parameters}

\subsubsection{Effect of $p H$}

The effect of $\mathrm{pH}$ on the ADS and ADS/EC process of copper and nickel ions in the solution has been established and it has been considered as the important parameter affecting the performance of $\mathrm{ADS}$ and $\mathrm{ADS} / \mathrm{EC}$ process in water and wastewater treatment efficiencies. In this study, the $\mathrm{pH}$ value was adjusted in the range of 2-8. (Fig. 4a) shows that $\mathrm{Cu}^{2+}$ removal in the ADS and ADS/EC coupling process at different $\mathrm{pH}$ values, with an AGWTR dose of $1 \mathrm{~g} . \mathrm{L}^{-1}$ at the current density of $1.19 \mathrm{~mA} / \mathrm{cm}^{2}$. The percentage of $\mathrm{Cu}^{2+}$ removal was a law at $\mathrm{pH} 2.0-4.0$ during the 
371 forms of functional groups (Nemeş and Bulgariu 2016). The maximum removal efficiency of $\mathrm{Cu}^{2+}$ 372 for the case of $\mathrm{ADS}$ was $76.2 \%$ at $\mathrm{pH}=6.0$. The same results were reported by (Patil et al. 2019).

373 While the ADS/EC process, the highest removal efficiency was achieved at $\mathrm{pH}=4.0$, due to the 374 presence of $\mathrm{Fe}(\mathrm{OH})_{3}$ in the solution highly depends upon the $\mathrm{pH}$ and concentration of $\mathrm{Fe}^{3+}$ in the 375 solution (Eq.3). Generally, in ADS/EC, the removal efficiency occurs at low pH due to the precipitation of $\mathrm{Fe}(\mathrm{OH})_{3}$ happened in the EC reactor. Similar results were observed by (Ilhan et al. $2019 b)$. In this process of coupling ADS/EC, the observed removal efficiency was $100 \%$ with a current density of $1.19 \mathrm{~mA} / \mathrm{Cm}^{2}$. Processes used in copper removal for studying the effect of $\mathrm{pH}$, are similar to nickel removal. Fig.4b shows the equilibrium removal efficiency of $\mathrm{Ni}^{2+}$ during the $\mathrm{ADS}$ and $\mathrm{ADS} / \mathrm{EC}$ processes. The removal efficiency for $\mathrm{Ni}^{2+}$ was $68.2 \%$ at $\mathrm{pH}=6.0$ during $\mathrm{ADS}$ while when we applied ADS/EC, the removal efficiency was $99.98 \%$ at the $\mathrm{pH}=4.0$. As we have seen in these results, the removal efficiency of $\mathrm{Cu}^{2+}$ is higher than $\mathrm{Ni}^{2+}$ for both cases (ADS and $\mathrm{ADS} / \mathrm{EC})$. Therefore, taking into account that the removal efficiency of both metal ions, when we increase $\mathrm{pH}$ from 4.0, resulting the amounts of $\mathrm{OH}^{-}$are increased in solution. Some of the hydroxide ions oxidized at the anode. This reaction inhibits the production of the same amount of iron ions, consequently, the removal of $\mathrm{Cu}^{2+}$ and $\mathrm{Ni}^{2+}$ decreased. So, original $\mathrm{pH}$ of the synthetized wastewater (i.e. 4.0) can be chosen because there is no addition of chemicals required. Therefore, due to the production and the consumption of those hydroxide ions from reaction, the removal of $\mathrm{Cu}^{2+}$ and $\mathrm{Ni}^{2+}$ in solution increase during $\mathrm{ADS}$ combined EC when the initial $\mathrm{pH}$ is low (Boujelben, Bouzid, and Elouear 2009). From the above explanations, we can be concluded that the initial pH after mixing the AGWTR with adsorbate, the increases of $\mathrm{Cu}^{2+}$ and $\mathrm{Ni}^{2+}$ removal compared to both ADS and EC alone. The same results have reported in (Al-Qodah and Al-Shannag 2017a).

Figure 4. Effect of $\mathrm{pH}$ on (a) $\mathrm{Cu} 2+$ and (b) $\mathrm{Ni2}+$ removal of the synthesized wastewater during the ADS and ADS/EC coupling processes $($ AGWTR dose $=1$ g.L-1, Initial conc. $=20 \mathrm{mg} . \mathrm{L}-1$ and Current density $=1.19$ $\mathrm{mA} / \mathrm{cm} 2$ ).

\subsubsection{Effect of electrolysis time}

Time is an important parameter that influences the water and wastewater treatment efficiency of ADS and ADS/EC coupling processes. As we have seen in Fig. 5, the effects of electrolysis time on copper and nickel removal were studied in the range of $10 \mathrm{~min}$ up to $180 \mathrm{~min}$ at an optimum current density of $1.19 \mathrm{~mA} / \mathrm{cm}^{2}$. Both metals $\mathrm{Cu}^{2+}$ and $\mathrm{Ni}^{2+}$ during the adsorption process, the 
401

402

403

404

405

406

407

408

409

410

411

412

413

414

415

416

417

418

419

420

421

422

423

424

425

426

427

428

429

observation reveals that the $\mathrm{Cu}^{2+}$ and $\mathrm{Ni}^{2+}$ removal increases with an increased adsorption contact time due to the presence of natural material of AGWTR as shown in Fig.5 (a and b). At 120 min of contact time, $1 \mathrm{~g}$ of AGWTR removed $73.51 \% \mathrm{of} \mathrm{Cu}^{2+}$ and $66.01 \%$ of $\mathrm{Ni}^{2+}$, respectively. This increase in both $\mathrm{Cu}^{2+}$ and $\mathrm{Ni}^{2+}$ adsorption at the beginning of the ADS process was happened because of the high availability of active surface sites on the AGWTR surface. When these available sites were readily occupied, the following slow ADS is generally considered as being affected by diffusion into the interior pore spaces of AGWTR (Ramesh et al. 2017).

In general, for the ADS coupled with the EC process, the quantity of the generated coagulant from iron electrodes increases with reaction time. The dissolution amount of iron was directly proportional to electrolysis time and therefore, the quantity of $\mathrm{Fe}^{2+}$ or $\mathrm{Fe}^{3+}$ ions and their flocs increased with the electrolysis time, resulting in higher removal efficiencies due to sweep coagulant and co-precipitation (Can et al. 2014). The removal efficiency of $\mathrm{Cu}^{2+}$ and $\mathrm{Ni}^{2+}$ increases with an increase of reaction time until it reaches a maximum of $30 \mathrm{~min}$ as the optimum time as observed Fig. 5. This Fig.5 ( $\mathrm{a}$ and b) showed that a total of $100 \%$ and $99.98 \%$ of copper and nickel ions were respectively removed in the synthesized wastewater at $30 \mathrm{~min}$ with a current density of $1.19 \mathrm{~mA} / \mathrm{cm}^{2}$. The removal of both metal ions $\mathrm{Cu}^{2+}$ and $\mathrm{Ni}^{2+}$ with electrolysis time occurred through the production of $\mathrm{Fe}(\mathrm{OH})_{3}$ "sweep flocs" which have large surface areas that are favorable for faster adsorption of $\mathrm{Cu}^{2+}$ and $\mathrm{Ni}^{2+}$ and adsorption of soluble organic compounds from wastewater into flocs that holds many complexes of ferric polymeric hydroxide which are responsible for eliminating the pollutants (Bazrafshan et al. 2015).

Figure 5. Effect of time on (a) $\mathrm{Cu} 2+$ and (b) Ni2+ removal synthesized wastewater during the ADS and ADS/EC coupling processes (Activated green waste tea dose $=1$ g.L-1, Initial conc. $=20 \mathrm{mg}$.L-1 and Current density $=1.19$ $\mathrm{mA} / \mathrm{cm} 2)$.

\subsubsection{Effect of AGWTR dose}

In this work, the effect of various adsorbent doses on the removal efficiency of copper and nickel for simple ADS and ADS/EC coupling process at different AGWTR doses were presented in Fig.6 ( $\mathrm{a}$ and $\mathrm{b}$ ) and the adsorbent was ranged in between $0.1-5 \mathrm{~g} . \mathrm{L}^{-1}$ during $120 \mathrm{~min}$. The results of the ADS experiments show that the efficiency of both metal ions $\left(\mathrm{Cu}^{2+}\right.$ and $\left.\mathrm{Ni}^{2+}\right)$ removal increase with the increase of the adsorbent dosage. In the case of the ADS process, the removal 
efficiencies for both metals were $86.70 \%$ and $64.33 \%$ for copper and nickel, respectively with 1 g. $\mathrm{L}^{-1}$ of AGWTR for contacting time of $120 \mathrm{~min}$. These results showed that with an increase of dosage, all copper and nickel ions in solutions may have interacted with the binding sites and then the highest $\mathrm{Cu}^{2+}$ and $\mathrm{Ni}^{2+}$ removal efficiencies are observed (Ibrahim et al. 2019). This may be happened due to the pretty number of ADS sites and more available surface area with the increase of adsorbent weight (Liu et al. 2017). When AGWTR dosage is higher, the ADS process onto the AGWTR surface was very fast and $\mathrm{Cu}^{2+}$ and $\mathrm{Ni}^{2+}$ concentrations become lower in the solutions. While the ADS/EC coupling process with compared to the simple ADS technique, the adsorbent was added in copper and nickel solution in the $\mathrm{EC}$ cell resulted in a slow increase of $\mathrm{Cu}^{2+}$ and $\mathrm{Ni}^{2+}$ removal. When a dose of AGWTR increased up to 1 g.L $\mathrm{L}^{-1}$, the copper and nickel removal reached $100 \%$ and $99.99 \%$ for $\mathrm{Cu}^{2+}$ and $\mathrm{Ni}^{2+}$ respectively instead of $86.70 \%$ and $64.33 \%$ achieved during simple ADS. The ADS/EC occurred with both electrolysis time of $30 \mathrm{~min}$ and current density of $1.19 \mathrm{~mA} / \mathrm{cm}^{2}$ for both metals removal. The metal removal percentages increase with an increase in the adsorbent doses and therefore, the adsorption sites on the AGWTR surface remain constant when the concentration of pollutants in the solution declines to the lowest value as shown in Fig.6 (a and b) (Akansha et al. 2020). Here $1 \mathrm{~g} \cdot \mathrm{L}^{-1}$ of AGWTR is enough to remove heavy metals in aqueous solutions at an instant level.

Figure 6. Effect of Adsorbent dose on (a) $\mathrm{Cu} 2+$ and (b) Ni2+ removal of the synthesized wastewater during the ADS and ADS/EC coupling processes (Initial conc. $=20 \mathrm{mg} . \mathrm{L}-1$ and Current density $=1.19 \mathrm{~mA} / \mathrm{cm} 2$ ).

\subsubsection{Effect of initial concentration}

The effects of the initial concentration on the $\mathrm{Cu}^{2+}$ and $\mathrm{Ni}^{2+}$ removal efficiencies at a constant AGWTR dosage of 1 g.L. $\mathrm{L}^{-1}$ are observed in Fig.7 (a and b). As planned, the $\mathrm{Cu}^{2+}$ and $\mathrm{Ni}^{2+}$ removal percentages were greater at lower initial $\mathrm{Cu}^{2+}$ and $\mathrm{Ni}^{2+}$ concentrations in the solutions for both processes (ADS and ADS/EC). For the case of ADS, we have investigated the maximum removal efficiency for both metal ions, by studying their different initial concentrations in their solutions. Here, the experiments are conducted to the different $\mathrm{Cu}^{2+}$ and $\mathrm{Ni}^{2+}$ concentrations of $20,40,60,80,100$ and $120 \mathrm{mg} . \mathrm{L}^{-1}$. In this study, the removal percentage of copper and nickel ions was $85.08 \%$ and $67.37 \%$, respectively of course in the adsorption process. These results were shown that the removal efficiencies were decreased with increasing $\mathrm{Cu}^{2+}$ and $\mathrm{Ni}^{2+}$ ion concentrations as observed in Fig.7(a and b). This has happened because $\mathrm{Cu}^{2+}$ and $\mathrm{Ni}^{2+}$ ions have 
quickly adhered to the ADS sites and these adsorption sites resulted from the adsorption efficiencies become higher (Abbaszadeh et al. 2016). Similar results have been obtained by Farihahusnah Hussin (Hussin et al., 2019). For the ADS/EC coupling process, the removal efficiency of $\mathrm{Cu}^{2+}$ and $\mathrm{Ni}^{2+}$ was also slightly decreased when their initial concentrations were beyond $20 \mathrm{mg} . \mathrm{L}^{-1}$ because of the slowest rate of coagulation; this means that the removal efficiencies were lower at the higher initial concentration values. Here, the removal efficiencies of both $\mathrm{Cu}^{2+}$ and $\mathrm{Ni}^{2+}$ ions in this process decreased from $99.98 \%$ to $89.13 \%$ and $99.20 \%$ to $84.46 \%$ respectively as increases from $20 \mathrm{mg} . \mathrm{L}^{-1}$ to $120 \mathrm{mg} . \mathrm{L}^{-1}$ in a time of $30 \mathrm{~min}$ as was shown in Fig.7(a and $b$ ). The reason is that the amount of coagulants generated were nearly the same and cannot be affected by initial concentration values. This quantity of sludge was unable to eliminate all initial $\mathrm{Cu}^{2+}$ and $\mathrm{Ni}^{2+}$ concentration values (Pizutti et al. 2019). The same results have been discussed by Zakaria (Zakaria et al. 2017).

Figure 7. Effect of Initial Concentration on (a) $\mathrm{Cu} 2+$ and (b) Ni2+ removal of the synthesized wastewater during the ADS and ADS/EC coupling processes (AGWTR= $1 \mathrm{~g} . \mathrm{L}-1$ and Current density $=1.19 \mathrm{~mA} / \mathrm{cm} 2$ ).

\subsubsection{Effect of current density}

Current density is one of the most important parameters which affect the effectiveness of the ADS/EC coupling process; it is used to determine the gas bubbles production and the coagulant dosage rate, growth and size of the flocs (Barhoumi et al. 2019; Ziouvelou, Tekerlekopoulou, and Vayenas 2019). Current density strongly affects both transfers of mass at the electrodes and solution mixing. To study the performance of $\mathrm{ADS} / \mathrm{EC}$ coupling process for $\mathrm{Cu}^{2+}$ and $\mathrm{Ni}^{2+}$ removal, with $1 \mathrm{~g}$ of AGWTR and 2 iron (1 for anode and other 1 for cathode) electrodes, experiments (four solutions for each metal ion) were evaluated out at the optimum parameters of electrocoagulation process: Electrolysis time $=30 \mathrm{~min},\left[\mathrm{Cu}^{2+}\right]$ and $\left[\mathrm{Ni}^{2+}\right]=20 \mathrm{mg} \cdot \mathrm{L}^{-1}, \mathrm{pH}=4.0$, inter-distance of electrodes $=1 \mathrm{~cm}$, sacrificial area electrodes $=84 \mathrm{~cm}^{2}$ and stirring speed $=150$ rpm. At low current density, an insignificant amount of anode dissolves and $\mathrm{Cu}^{2+}$ and $\mathrm{Ni}^{2+}$ removal decrease (Ilhan et al., 2019a).

In general, as it is known, the removal of metal ions from wastewaters increases with the increase of dosages of iron in chemical coagulation (Vieno, Tuhkanen, and Kronberg 2006). Both copper and nickel ions removal in ADS/EC are thus expected to be determined by the amount of hydrous oxides produced in the solution. As stated by Faraday's low, the mass of dissolved iron 
(Eq. 14) is directly proportional to current density (j) (Al-Qodah and Al-Shannag 2017b). As a result, the creation of metal-hydrous ferric oxide complexes is typically used to define $\mathrm{Cu}^{2+}$ and $\mathrm{Ni}^{2+}$ elimination by ADS coupled with EC. Fig.8 (a and b), displays that in $30 \mathrm{~min}$, the removal efficiencies for both $\mathrm{Cu}^{2+}$ and $\mathrm{Ni}^{2+}$ are $100 \%$ and $99.99 \%$ respectively and also these results showed that the removal efficiency of both metals are higher than those we found in the case of electrocoagulation alone. Thus coupling the ADS process to the EC on AGWTR is very effective and also the target of the reduction of energy consumption was achieved. As we observed in the results, we found that with increasing current density, the removal efficiency for both metal ions increases due to higher dissolution of iron electrode material with higher formation rate of hydroxides resulting from co-precipitation. Also, production of more sludge is obtained from iron electrodes due to that higher rate of dissolution of anode and those amounts of sludge enhance the removal of both $\mathrm{Cu}^{2+}$ and $\mathrm{Ni}^{2+}$ efficiency due to sweep at elevated current density. Additionally, a generation of more bubbles was observed at the higher current density of $1.19 \mathrm{~mA} / \mathrm{cm}^{2}$ and it increases both mixing and metal removal efficiency. (Panizza and Cerisola 2010). The other previous researches have reported also that the metal ions removal efficiency increase with an increase of current density (Al-Qodah \& Al-Shannag, 2017; Elabbas et al., 2020b).

Figure 8. Effect of Current density on (a) $\mathrm{Cu} 2+$ and (b) Ni2+ removal of the synthesized wastewater during the ADS and ADS/EC coupling processes (Activated green tea waste dose $=1 \mathrm{~g} . \mathrm{L}-1, \mathrm{pH}=6$, Current density $=1.19 \mathrm{~mA} / \mathrm{cm} 2$, Initial conc. $=20 \mathrm{mg} . \mathrm{L}-1$ and contact time $=120 \mathrm{~min}$ ).

\subsubsection{Isothermal Study}

In the combination of $\mathrm{ADS}$ with $\mathrm{EC}$, the adsorption isotherm for removing $\mathrm{Cu}^{2+}$ and $\mathrm{Ni}^{2+}$ from synthesized wastewater by AGWTR was investigated using Freundlich and Langmuir isotherm models. The correlation coefficients of both isotherm models are determined with their theoretical parameters and are observed in Table 1. The results obtained from experiments of both metal ion showed that Langmuir isotherm was the best-fitted model with higher regression coefficients of $\mathrm{R}^{2}=0.997$ and $\mathrm{R}^{2}=0.912$ compared to the Freundlich isotherms $\left(\mathrm{R}^{2}=0.996\right.$ and $\mathrm{R}^{2}=0.944$ ) for copper and nickel ions, respectively (Fig. 9). The maximum regression coefficient indicated that copper and nickel ions are absorbed by AGWTR, forming a monolayer on its surface. For both copper and nickel ions, the maximum adsorption capacity of the adsorbent was 
estimated using the Langmuir isotherm (15.6 mg.g-1) and (15.9 mg.g-1). These studies were carried out with a working volume of $100 \mathrm{~mL}$ of wastewater combined with $1 \mathrm{~g}$ of AGWTR, agitation speed of $150 \mathrm{rpm}$, and a working temperature of $30^{\circ} \mathrm{C}$, and an initial concentration of both $\mathrm{Cu}^{2+}$ and $\mathrm{Ni}^{2+}$ of $20 \mathrm{mg} . \mathrm{L}^{-1}$ of adsorbate. Here, Langmuir adsorption states that at special sites of a homogenous surface of the AGWTR consisting of a fixed number of similar sorption sites, adsorption happens and the process of adsorption occurs as the saturation of these sorption sites (Jiang, Pang, and Liao 2009). The adsorption was limited to the monolayer layer coverage of both metal ions. Langmuir plot of Ce/ $\mathrm{q}_{\mathrm{e}}$ versus Ce was plotted in Langmuir isotherm and a straight line was observed. The Langmuir constant parameters qm and KL were computed using (Eq.8) as mentioned previously. and are observed in table 1. The Langmuir isotherm type was discussed and we found that the adsorption is favorable for adsorption of both $\mathrm{Cu}^{2+}$ and $\mathrm{Ni}^{2+}$ due to $\mathrm{R}_{\mathrm{L}}$ (the dimensionless constant separation factor) (Eq.9), which was ranging from $0<\mathrm{R}_{\mathrm{L}}<1$ and the values of our $\mathrm{R}_{\mathrm{L}}$ were found to be 0.04 for both metals removal. Similar results were discussed where tartrazine adsorption onto Moringa oleifera seed (Reck et al. 2018), dye adsorption onto tea waste (Khosla, Kaur, and Dave 2013) and Methylene Blue Dye from industrial wastewater using prepared activated Carbon (Rahimian and Zarinabadi 2020).

\subsubsection{Table 1: Isotherm and Kinetic study parameters for $\mathrm{Cu}^{2+}$ and $\mathrm{Ni}^{2+}$ adsorption}

Figure 9. Adsorption/electrocoagulation isotherms: (a) Langmuir isotherm for $\mathrm{Cu} 2+$, (b) Freundlich isotherm for $\mathrm{Cu} 2+$, Langmuir isotherm for Ni2+ and Freundlich isotherm for Ni2+.

\subsubsection{Kinetic studies}

To investigate the kinetics models for removal of $\mathrm{Cu}^{2+}$ and $\mathrm{Ni}^{2+}$ by conventional $\mathrm{ADS}$ and ADS combining with EC process, the linear pseudo-first-order and pseudo-second-order kinetic models were analyzed to fit the experimental kinetic data. For pseudo-first-order, $\mathrm{K}_{1}$ was developed from the plotted slope of $\ln \left(q_{e}-q_{t}\right)$ versus $\mathrm{t}$ (Eq.11) while the pseudo-second-order kinetic model was plotted by taking $\frac{t}{q_{t}}$ versus $\mathrm{t}$ (Eq.12). They were tested according to the mentioned models and the correlation coefficients with the rate constants in both models are shown in table 1. A linear relationship was calculated, $\mathrm{K}_{2}$ provided from intercept and $\mathrm{q}_{\mathrm{e}}$ (obtained from the slope) values are determined. The comparison of values of coefficient $\mathrm{R}^{2}$ derived from the plots of both pseudo-first order and pseudo-second order of kinetic models were computed and the 
results were showed that the coupling ADS/EC process is led by pseudo-second order of kinetic model for both metal ions removal. For copper ions and Nickel ions removal, in pseudo-first order kinetic model, $\mathrm{q}_{\mathrm{e}}\left(1.055 \mathrm{mg} \cdot \mathrm{g}^{-1}\right), \mathrm{K}_{1}\left(0.006 \mathrm{~h}^{-1}\right), \mathrm{R}^{2}=0.945$ and $\mathrm{q}_{\mathrm{e}}\left(0.977 \mathrm{mg} \cdot \mathrm{g}^{-1}\right), \mathrm{K}_{1}\left(0.0184 \mathrm{~h}^{-1}\right)$, $\mathrm{R}^{2}=0.926$, respectively. For pseudo-second order kinetic model, $\mathrm{q}_{\mathrm{e}}\left(0.23 \mathrm{mg} \cdot \mathrm{g}^{-1}\right), \mathrm{K}_{2}\left(7.61 \mathrm{~h}^{-1}\right)$, $\mathrm{R}^{2}=0.980$ for $\mathrm{Cu}^{2+}$ and $\mathrm{q}_{\mathrm{e}}\left(0.15 \mathrm{mg} \cdot \mathrm{g}^{-1}\right), \mathrm{K}_{2}\left(9.3 \mathrm{~h}^{-1}\right), \mathrm{R}^{2}=0.946$ for $\mathrm{Ni}^{2+}$ could be observed from calculation. These facts showed that pseudo-second equation model is the best fit to the experimental data with high $\mathrm{R}^{2}$ and also sorption of copper and nickel follow the pseudo-secondorder kinetic model as shown in (Fig.10). Which meant that the adsorption rate was mainly regulated by chemisorption.

Figure 10. Adsorption/electrocoagulation Kinetic study (a) pseudo-first kinetic for $\mathrm{Cu} 2+$, (b) pseudo-second kinetic for $\mathrm{Cu} 2+$, (c) pseudo-first kinetic for Ni2+ and (d) pseudo-second kinetic for Ni2+.

\subsubsection{Energy consumption and amount of dissolved electrodes}

The energy consumption cost computations are necessary to calculate the feasibility of ADS/EC application, because not only to investigate the greatest interest of the metal removal efficiencies but also the consumption of power consumed for this technology application. As we have discussed above (Eq.13). Here, the energy consumption has been calculated and we fund 0.4 $\mathrm{kWh} / \mathrm{m}^{3}$. Thus, this result is better than other results reported by other researchers such as (Akansha et al. 2020; Wagle et al. 2020).

\subsubsection{Competitive adsorption and electrocoagulation in binary metal systems}

In this research, the competitive ADS/EC of copper and nickel ions in their binary solutions were studied in a similar way as described above. These experiments were investigated at a temperature of $30^{\circ} \mathrm{C}$ at initial $\mathrm{pH}$ of 6.0 . The main objective of this experiment was to investigate the effect of both $\mathrm{Cu}^{2+}$ and $\mathrm{Ni}^{2+}$ coexistence on the total capacity of adsorption in presence of AGWTR combined with Fe-electrode. The result was observed in (Fig. 11). As observed in that figure, the values of the adsorbed amount of $\mathrm{Cu}^{2+}$ and $\mathrm{Ni}^{2+}$ are found and are described by referring to the following conditions (the initial $\mathrm{pH}$ of the solutions was kept at $6.0,1 \mathrm{~g}$ of AGWTR per 20 $\mathrm{mL}$ of solution at $30^{\circ} \mathrm{C}$ and reaction time of $30 \mathrm{~min}$ for both metals) which were ranging from 1.35 to $1.89 \mathrm{mg} . \mathrm{L}^{-1}$ and 1.22 to $1.83 \mathrm{mg} \cdot \mathrm{L}^{-1}$ for copper and nickel ions, respectively that were not 
577 greater than those for single-component solutions (1.44 to $2.0 \mathrm{mg} . \mathrm{L}^{-1}$ and 1.39 to $1.99 \mathrm{mg} . \mathrm{L}^{-1}$ for

$578 \mathrm{Cu}^{2+}$ and $\mathrm{Ni}^{2+}$, respectively). Single metal ion present impeded through the uptake of another

579 metal in the system, and both metals uptake were little lower than that in a single system. This

580 showed that functional group of AGWTR surface have a relatively strongest affinity for copper

581 ions than nickel ions.

582

583

584

585

586

587

588

589

590

591

592

593

594

595

596

597

598

599

600

601

602

603

Figure 11. Combination of $\mathrm{Cu} 2+$ and $\mathrm{Ni} 2+$ ions in solution with $20 \mathrm{mg} \cdot \mathrm{L}-1$ at $\mathrm{T}=30^{\circ} \mathrm{C}$

\subsubsection{Reusability study}

The reusability of the adsorbent is a very important that aspect of the water treatment process. In this study of reusing material especially AGWTR and Fe-electrode, we conducted ADS/EC processes using $\mathrm{Cu}^{2+}$ and $\mathrm{Ni}^{2+}$ as pollutants. ADS coupled with EC processes are similar to that we have discussed in experimental part 2.5. After ADS/EC, the sludge was separated by filtration procedure using Whatman microfiber filter of $0.45 \mu \mathrm{m}$ pore size. To regenerate our materials, water and Hydrochloric acid of $0.1 \mathrm{M}$ were used for washing of $\mathrm{Cu}^{2+}$ and $\mathrm{Ni}^{2+}$ that were adsorbed by AGWTR at the previous stage and no solvent has been used here. As it is observed in Fig. 12, the removal efficiency of $\mathrm{Cu}^{2+}$ and $\mathrm{Ni}^{2+}$ is $94.87 \%$ and $91.99 \%$, respectively. It is perfect, stable, easy and it can be applied repeated ADS coupled with EC of heavy metals. A cycle of this study was repeated five times for deciding the reusability potential of AGWTR and Fe as adsorbent and electrode, respectively.

Figure 12. Maximum removal efficiency with reuse of the generated $\mathrm{AGWTR}$ for $\mathrm{Cu}^{2+}$ and $\mathrm{Ni}^{2+}$ removal using ADS/EC process. (AGWTR $=1 \mathrm{~g} ; \mathrm{Cu}^{2+}$ and $\mathrm{Ni}^{2+}=20 \mathrm{mg} \cdot \mathrm{L}^{-1}$ at $\mathrm{T}=30^{\circ} \mathrm{C}$ ).

Table 2. Results of ADS/EC of Conc. $\mathrm{Cu}^{2+}$ and $\mathrm{Ni}^{2+}$ by AGWTR from different water samples.

Table 3. Comparison of maximum adsorption capacities and operation parameters of previous research related to waste tea residue adsorbents.

\section{Conclusions}

In this work, the removal of $\mathrm{Cu}^{2+}$ and $\mathrm{Ni}^{2+}$ from synthesized wastewater via ADS and ADS coupled with EC onto activated green waste tea residue was studied in detail. It was observed that our AGWTR is successfully proved as a cheap, cost-effective and sustainable adsorbent for heavy 
metal removal in synthetic wastewater. The results of operating parameters for both metal ions were: $\mathrm{pH}=6.0, \mathrm{t}=120 \mathrm{~min}, \mathrm{AGWTR}$ dose $=1 \mathrm{~g}$ and initial conc. $=20 \mathrm{mg}$.L for single ADS. While in $\mathrm{ADS} / \mathrm{EC}$ process was optimized at $\mathrm{pH}=4.0, \mathrm{t}=30 \mathrm{~min}, \mathrm{AGWTR}$ dose $=1 \mathrm{~g}$, initial conc. $=20$ mg. $\mathrm{L}^{-1}$ and $j=1.19 \mathrm{~mA} / \mathrm{cm}^{2}$. Their removal efficiencies for $\mathrm{Cu}^{2+}$ and $\mathrm{Ni}^{2+}$ were $73.51 \%$ and $66.01 \%$ in single ADS while in ADS/EC process, $100 \%$ and $99.9 \%$ for $\mathrm{Cu}^{2+}$ and $\mathrm{Ni}^{2+}$, respectively. Our AGWTR was prepared without applying neither chemicals nor any activating agents. The adsorption isotherm showed that Langmuir isotherm was the best-fitted model compared to the Freundlich isotherm model. The maximum adsorption capacity of AGWTR is obtained to be 15.6 and $15.9 \mathrm{mg} \cdot \mathrm{g}^{-1}$ for $\mathrm{Cu}^{2+}$ and $\mathrm{Ni}^{2+}$, respectively. The kinetic study of both metals followed a pseudo-second-order kinetic model. SEM shows folded, cracks and various large holes on the external surfaces of the activated green tea residue which look like the structure observed on GO generated from the graphite. Sorption on a single system was found to be more effective in producing a desired or intended results than the one on the binary system. Finally, based on the results found in this work, it may be concluded that ADS combined with EC process is environmental friendly technology rather than single ADS or EC technology for wastewater treatment and can be applied on large scale for municipal and industrial wastewater treatment.

\section{Authors Contributions}

Conceptualization and writing - original draft preparation: [Jean Claude Nizeyimana]. Supervision and Resources: [Shanshan Lin]. Formal analysis and investigation: [Junaid Khan, [Wu Yifeng]. Writing - review and editing: [Shanshan Lin] and Data collection: [Jean Claude Nizeyimana], [Junaid Khan], [Liu Xiangru] and [Han dongxu].

\section{Funding}

This study was funded by the National Natural Science Foundation of China (NSFC: 41772236) and the Science and Technology Department of Changchun City (17SS027).

\section{Data availability}

All data generated or analyzed during this study are included in this article. 
631 Declarations

632 Ethics approval and consent to participate

633 Not applicable.

634 Consent for publication

635 Not applicable.

636 Competing interests

637 The authors declare no competing interests. 


\section{Reference}

Abbaszadeh, Sahar et al. 2016. "Treatment of Lead-Contaminated Water Using Activated Carbon Adsorbent from Locally Available Papaya Peel Biowaste." Journal of Cleaner Production 118: 210-22.

Ahmaruzzaman, M., and S. Laxmi Gayatri. 2010. “Activated Tea Waste as a Potential Low-Cost Adsorbent for the Removal of $\mathrm{p}$-Nitrophenol from Wastewater." Journal of Chemical and Engineering Data 55(11): 4614-23.

Ahuja, Atul K, Prem Singh, and Varinderjit Singh. 2019. "Physico-Chemical Characterization of Ground Water with Reference to Water Quality Index and Their Seasonal Variation in Vicinity of Thermal Power Plant at Yamuna Nagar, Haryana.” (April).

Akansha, J. et al. 2020. "Treatment of Dairy Industry Wastewater by Combined Aerated Electrocoagulation and Phytoremediation Process." Chemosphere 253: 126652. https://doi.org/10.1016/j.chemosphere.2020.126652.

Al-Qodah, Zakaria, and Mohammad Al-Shannag. 2017a. "Heavy Metal Ions Removal from Wastewater Using Electrocoagulation Processes: A Comprehensive Review." Separation Science and Technology (Philadelphia) 52(17): 2649-76.

—. 2017b. "Heavy Metal Ions Removal from Wastewater Using Electrocoagulation Processes: A Comprehensive Review." Separation Science and Technology (Philadelphia) 52(17): 2649-76. https://doi.org/10.1080/01496395.2017.1373677.

Ali, I. H., and A. A. Ateeg. 2015. "Study of Soil Pollutants in Omdurman Industrial Area, Sudan, Using X-Ray Fluorescence Technique." International Journal of Environmental Research 9(1): 291-94.

Aravind, Priyadharshini, Hosimin Selvaraj, Sergio Ferro, and Maruthamuthu Sundaram. 2016. "An Integrated (Electro- and Bio-Oxidation) Approach for Remediation of Industrial Wastewater Containing Azo-Dyes: Understanding the Degradation Mechanism and Toxicity Assessment." Journal of Hazardous Materials 318: 203-15. http://dx.doi.org/10.1016/j.jhazmat.2016.07.028. 
Barhoumi, Afef et al. 2017. "Combining Adsorption on Activated Carbon with Electrocoagulation Process for Copper Removal from Used Water." Desalination and Water Treatment 83: 21221.

- 2019. "High-Rate Humic Acid Removal from Cellulose and Paper Industry Wastewater by Combining Electrocoagulation Process with Adsorption onto Granular Activated Carbon." $\begin{array}{lllll}\text { Industrial Crops } & \text { and }\end{array}$ https://doi.org/10.1016/j.indcrop.2019.111715.

Bazrafshan, Edris, Leili Mohammadi, Alireza Ansari-Moghaddam, and Amir Hossein Mahvi. 2015. "Heavy Metals Removal from Aqueous Environments by Electrocoagulation Process A Systematic Review." Journal of Environmental Health Science and Engineering 13(1). http://dx.doi.org/10.1186/s40201-015-0233-8.

Boujelben, N., J. Bouzid, and Z. Elouear. 2009. "Adsorption of Nickel and Copper onto Natural Iron Oxide-Coated Sand from Aqueous Solutions: Study in Single and Binary Systems.” Journal of Hazardous Materials 163(1): 376-82.

Buema, Gabriela et al. 2021. "Adsorption Performance of Modified Fly Ash for Copper Ion Removal from Aqueous Solution.” Water (Switzerland) 13(2).

Can, Berrin Zeliha, Recep Boncukcuoglu, Alper Erdem Yilmaz, and Baybars Ali Fil. 2014. "Effect of Some Operational Parameters on the Arsenic Removal by Electrocoagulation Using Iron Electrodes.” Journal of Environmental Health Science and Engineering 12(1): 1-10.

Cherdchoo, Wachiraphorn, Srisuda Nithettham, and Jittima Charoenpanich. 2019. "Removal of Cr(VI) from Synthetic Wastewater by Adsorption onto Coffee Ground and Mixed Waste Tea." Chemosphere 221: 758-67. https://doi.org/10.1016/j.chemosphere.2019.01.100.

Deng, Zhiwen et al. 2021. "Green Tea Polyphenol Nanoparticle as a Novel Adsorbent to Remove $\mathrm{Pb} 2+\quad$ from $\quad$ Wastewater.” $\quad$ Materials Letters 284: 128986. https://doi.org/10.1016/j.matlet.2020.128986.

Elabbas, Saliha et al. 2020. "Eggshell Adsorption Process Coupled with Electrocoagulation for Improvement of Chromium Removal from Tanning Wastewater.” International Journal of Environmental Analytical Chemistry: 0-15. 
Genchi, Giuseppe et al. 2020. "Nickel: Human Health and Environmental Toxicology." International Journal of Environmental Research and Public Health 17(3).

Goodarzvand Chegini, Zahra, Hessam Hassani, Ali Torabian, and Seyed Mehdi Borghei. 2020. "Enhancement of PMS Activation in an UV/Ozone Process for Cyanide Degradation: A Comprehensive Study." Pigment and Resin Technology 49(5): 409-14.

Hussin, Farihahusnah, Mohamed Kheireddine Aroua, and Małgorzata Szlachtac. 2019. "Combined Solar Electrocoagulation and Adsorption Processes for Pb(II) Removal from Aqueous Solution." Chemical Engineering and Processing - Process Intensification 143(August): 107619. https://doi.org/10.1016/j.cep.2019.107619.

Ibrahim, Ahmed G. et al. 2019. "Chitosan-g-maleic Acid for Effective Removal of Copper and Nickel Ions from Their Solutions." International Journal of Biological Macromolecules 121: 1287-94. https://doi.org/10.1016/j.ijbiomac.2018.10.107.

Ilhan, Fatih et al. 2019a. "Electrocoagulation Process for the Treatment of Metal-Plating Wastewater: Kinetic Modeling and Energy Consumption." Frontiers of Environmental Science and Engineering 13(5): 1-8.

- 2019b. "Electrocoagulation Process for the Treatment of Metal-Plating Wastewater: Kinetic Modeling and Energy Consumption." Frontiers of Environmental Science and Engineering 13(5).

Imron, Muhammad Fauzul, Setyo Budi Kurniawan, and Harmin Sulistiyaning Titah. 2019. "Potential of Bacteria Isolated from Diesel-Contaminated Seawater in Diesel Biodegradation." Environmental Technology and Innovation 14: 100368. https://doi.org/10.1016/j.eti.2019.100368.

Jayasinghe, H D R P, M Riswan, and P Ishaq. 2021. "Water Scarcity in Aligambai Village, Alayadivembu Divisional Secretariat, Sri Lanka." Shanlax International Journal of Arts, Science and Humanities 8(3): 6-12.

Jeppu, Gautham P., and T. Prabhakar Clement. 2012. "A Modified Langmuir-Freundlich Isotherm Model for Simulating PH-Dependent Adsorption Effects." Journal of Contaminant Hydrology 129-130(March): 46-53. http://dx.doi.org/10.1016/j.jconhyd.2011.12.001. 
Jiang, Yu, Hao Pang, and Bing Liao. 2009. "Removal of Copper(II) Ions from Aqueous Solution by Modified Bagasse.” Journal of Hazardous Materials 164(1): 1-9.

Khosla, Ekta, Satindar Kaur, and Pragnesh N. Dave. 2013. "Tea Waste as Adsorbent for Ionic Dyes." Desalination and Water Treatment 51(34-36): 6552-61.

Lapointe, Mathieu, Jeffrey M. Farner, Laura M. Hernandez, and Nathalie Tufenkji. 2020. "Understanding and Improving Microplastic Removal during Water Treatment: Impact of Coagulation and Flocculation.” Environmental Science and Technology 54(14): 8719-27.

Liakos, Efstathios V. et al. 2021. "Adsorption Evaluation for the Removal of Nickel, Mercury, and Barium Ions from Single-Component and Mixtures of Aqueous Solutions by Using an Optimized Biobased Chitosan Derivative." Polymers 13(2): 1-20.

Liu, Su et al. 2017. "Facile Synthesis of Cu(II) Impregnated Biochar with Enhanced Adsorption Activity for the Removal of Doxycycline Hydrochloride from Water." Science of the Total Environment 592: 546-53. http://dx.doi.org/10.1016/j.scitotenv.2017.03.087.

Mehta, Dhiraj, Poonam Mondal, and Suja George. 2016. "Utilization of Marble Waste Powder as a Novel Adsorbent for Removal of Fluoride Ions from Aqueous Solution." Journal of Environmental Chemical Engineering 4(1): 932-42. http://dx.doi.org/10.1016/j.jece.2015.12.040.

Moussa, Dina T., Muftah H. El-Naas, Mustafa Nasser, and Mohammed J. Al-Marri. 2017. “A Comprehensive Review of Electrocoagulation for Water Treatment: Potentials and Challenges." Journal of Environmental Management 186: 24-41. http://dx.doi.org/10.1016/j.jenvman.2016.10.032.

Myllymäki, Pekka, Riikka Lahti, Henrik Romar, and Ulla Lassi. 2018. "Removal of Total Organic Carbon from Peat Solution by Hybrid Method-Electrocoagulation Combined with Adsorption." Journal of Water Process Engineering 24(January): 56-62. https://doi.org/10.1016/j.jwpe.2018.05.008.

Narendrakumar, G, and P Senthil. 2020. "Adsorption of Chromium from Aqueous Solution by Lignocellulosic Biomass (Pinus Palustris): Studies on Equilibrium Isotherm, and Kinetics.” Journal of Environmental Treatment Techniques 9(1): 77-84. 
Nemeş, LǍcrǍmioara, and Laura Bulgariu. 2016. "Optimization of Process Parameters for Heavy Metals Biosorption onto Mustard Waste Biomass." Open Chemistry 14(1): 175-87.

Nigam, Mohit, Sunil Rajoriya, Shraddha Rani Singh, and Pradeep Kumar. 2019. "Adsorption of $\mathrm{Cr}$ (VI) Ion from Tannery Wastewater on Tea Waste: Kinetics, Equilibrium and Thermodynamics Studies.” Journal of Environmental Chemical Engineering 7(3): 103188. https://doi.org/10.1016/j.jece.2019.103188.

Nikolic, Milica, Rohan Jeffry Robert, and C.R. Girish. 2019. "The Adsorption of Cadmium, Nickel, Zinc, Copper and Lead from Wastewater Using Tea Fiber Waste." Journal of Engineering and Applied Sciences 14(20): 7743-55.

Pandiarajan, Aarthi, Ramakrishnan Kamaraj, and Subramanyan Vasudevan. 2017. "Enhanced Removal of Cephalosporin Based Antibiotics (CBA) from Water by One-Pot Electrosynthesized $\mathrm{Mg}(\mathrm{OH}) 2$ : A Combined Theoretical and Experimental Study to Pilot Scale." New Journal of Chemistry 41(11): 4518-30.

Panizza, Marco, and Giacomo Cerisola. 2010. "Applicability of Electrochemical Methods to Carwash Wastewaters for Reuse. Part 2: Electrocoagulation and Anodic Oxidation Integrated Process." Journal of Electroanalytical Chemistry 638(2): 236-40. http://dx.doi.org/10.1016/j.jelechem.2009.11.003.

Patil, Chandrashekhar S. et al. 2019. "Waste Tea Residue as a Low Cost Adsorbent for Removal of Hydralazine Hydrochloride Pharmaceutical Pollutant from Aqueous Media: An Environmental Remediation." Journal of Cleaner Production 206: 407-18.

Paulino, Alexandre T. et al. 2006. "Novel Adsorbent Based on Silkworm Chrysalides for Removal of Heavy Metals from Wastewaters." Journal of Colloid and Interface Science 301(2): 47987.

Pizutti, Janaína Terhorst, Rita de Cassia Dos Santos, Marcelo Hemkemeier, and Jeferson Steffanello Piccin. 2019. "Electrocoagulation Coupled Adsorption for Anaerobic Wastewater Post-Treatment and Reuse Purposes." Desalination and Water Treatment 160: 144-52.

Rahimian, Ronak, and Soroush Zarinabadi. 2020. "A Review of Studies on the Removal of Methylene Blue Dye from Industrial Wastewater Using Activated Carbon Adsorbents Made 
from Almond Bark." Progress in Chemical and Biochemical Research Journal homepage 3(3): 251-68. www.pcbiochemres.com.

Ramesh, Thimmasandra Narayan, Devarahosahally Veeranna Kirana, Ashwathaiah Ashwini, and T. R. Manasa. 2017. "Calcium Hydroxide as Low Cost Adsorbent for the Effective Removal of Indigo Carmine Dye in Water." Journal of Saudi Chemical Society 21(2): 165-71. http://dx.doi.org/10.1016/j.jscs.2015.03.001.

Reck, Isabela Maria et al. 2018. "Removal of Tartrazine from Aqueous Solutions Using Adsorbents Based on Activated Carbon and Moringa Oleifera Seeds." Journal of Cleaner Production 171: 85-97. http://dx.doi.org/10.1016/j.jclepro.2017.09.237.

Santos, Dércia et al. 2020. "Toxicological Effects Induced on Early Life Stages of Zebrafish (Danio Rerio) after an Acute Exposure to Microplastics Alone or Co-Exposed with Copper.” Chemosphere 261: 127748. https://doi.org/10.1016/j.chemosphere.2020.127748.

Si, Wantong et al. 2015. "Health Risks of Metals in Contaminated Farmland Soils and Spring Wheat Irrigated with Yellow River Water in Baotou, China." Bulletin of Environmental Contamination and Toxicology 94(2): 214-19.

Sikdar, Dolanchapa, Sudipta Goswami, and Papita Das. 2020. “Activated Carbonaceous Materials from Tea Waste and Its Removal Capacity of Indigo Carmine Present in Solution: Synthesis, Batch and Optimization Study." Sustainable Environment Research 30(1).

Singh Thakur, Lokendra, Mukesh Parmar -, and Mukesh Parmar. 2013. "Adsorption of Heavy Metal ( $\mathrm{Cu} 2+, \mathrm{Ni} 2+$ and $\mathrm{Zn} 2+)$ from Synthetic Waste Water by Tea Waste Adsorbent." International Journal of Chemical and Physical Sciences 2(6): 6-19. http://link.springer.com/10.1007/BF03326248.

Syaichurrozi, Iqbal, Sarto Sarto, Wahyudi Budi Sediawan, and Muslikhin Hidayat. 2021. "Effect of Current and Initial Ph on Electrocoagulation in Treating the Distillery Spent Wash with Very High Pollutant Content." Water (Switzerland) 13(1).

Uzun, Başak Burcu et al. 2010. "Synthetic Fuel Production from Tea Waste: Characterisation of Bio-Oil and Bio-Char." Fuel 89(1): 176-84.

Vieno, N., T. Tuhkanen, and L. Kronberg. 2006. "Removal of Pharmaceuticals in Drinking Water 
807 Wagle, Dipendra, Che Jen Lin, Tabish Nawaz, and Heather J. Shipley. 2020. "Evaluation and Optimization of Electrocoagulation for Treating Kraft Paper Mill Wastewater." Journal of Environmental

Chemical

Engineering

8(1):

103595. https://doi.org/10.1016/j.jece.2019.103595.

811

812

813

814

815

816

817

818

819

820

821

822

823

824

825

826

827

828

Watari, Takahiro et al. 2021. "Anaerobic Biological Treatment of EG/PG Water-Soluble Copolymer Coupled with down-Flow Hanging Sponge Reactor." Environmental Technology and Innovation 21. https://doi.org/10.1016/j.eti.2020.101325.

Yao, Ying et al. 2014. "Characterization and Environmental Applications of Clay-Biochar Composites." Chemical Engineering Journal 242: 136-43. http://dx.doi.org/10.1016/j.cej.2013.12.062.

Yıldız, Sayiter, Mehmet Çekim, and Turgay Dere. 2017. "Biosorption of Cu2+ and Ni2+ Ions from Synthetic Waters." Applied Biochemistry and Biotechnology 183(1): 332-47.

Zakaria, Muhammad Razlan, Muhammad Helmi Abdul Kudus, Hazizan Md. Akil, and Mohd Zharif Mohd Thirmizir. 2017. "Comparative Study of Graphene Nanoparticle and Multiwall Carbon Nanotube Filled Epoxy Nanocomposites Based on Mechanical, Thermal and Dielectric Properties." Composites Part B: Engineering 119: 57-66. http://dx.doi.org/10.1016/j.compositesb.2017.03.023.

Ziouvelou, Athina, Athanasia G. Tekerlekopoulou, and Dimitris V. Vayenas. 2019. "A Hybrid System for Groundwater Denitrification Using Electrocoagulation and Adsorption.” Journal of Environmental

Management 249(June): 109355. https://doi.org/10.1016/j.jenvman.2019.109355. 
Figures

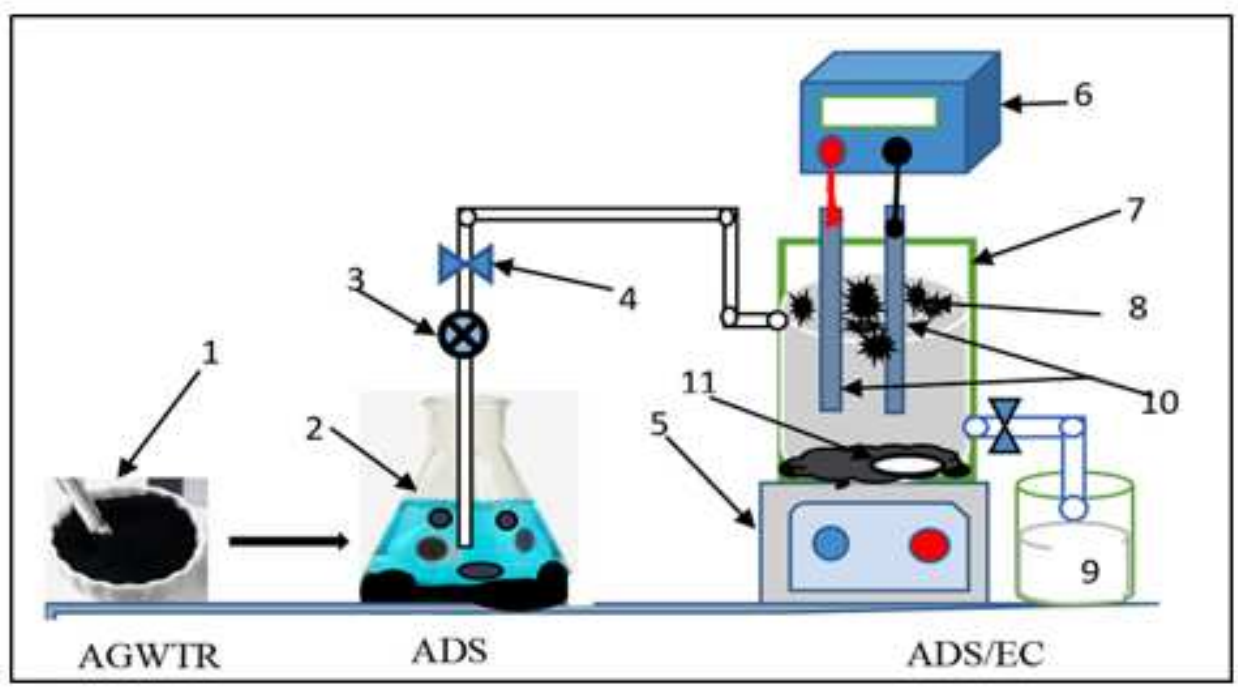

Figure 1

The apparatus layout used in the experiments: 1. AGWTR, 2. ADS Vessel; 3.pump; 4. Control valve; 5. Stiller/Agitator; 6. direct current power source; 7. Electro electric cell; 8. Flocs; 9. treated water in reception tank; 10. Iron electrodes and 11. Magnetic stiller 

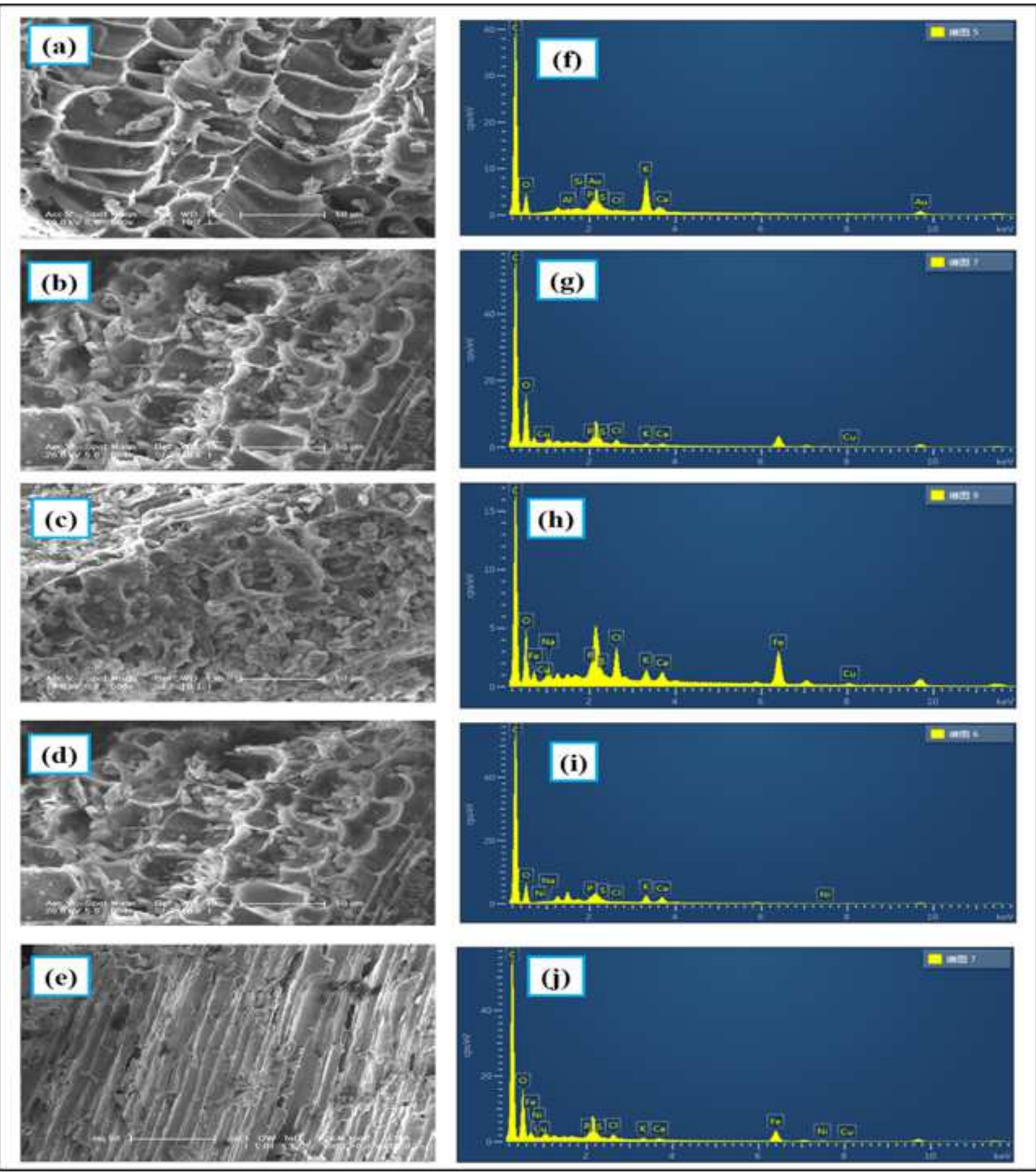

\section{Figure 2}

(a) SEM image of AGWTR before adsorption, (b) SEM image of AGWTR after adsorption of Cu2+, (c) SEM image of AGWTR after ADS/EC of Cu2+, (d) SEM image of AGWTR after adsorption of Ni2+, (e) SEM image of AGWTR after ADS/EC of Ni2+. (f) EDS spectra of AGWTR before adsorption, (g) EDS spectra of AGWTR after adsorption of Cu2+, (h) EDS spectra of AGWTR after ADS/EC of Cu2+,(i) EDS spectra of AGWTR after adsorption of Ni2+ and (j) EDS spectra of AGWTR after ADS/EC of Ni2+. 

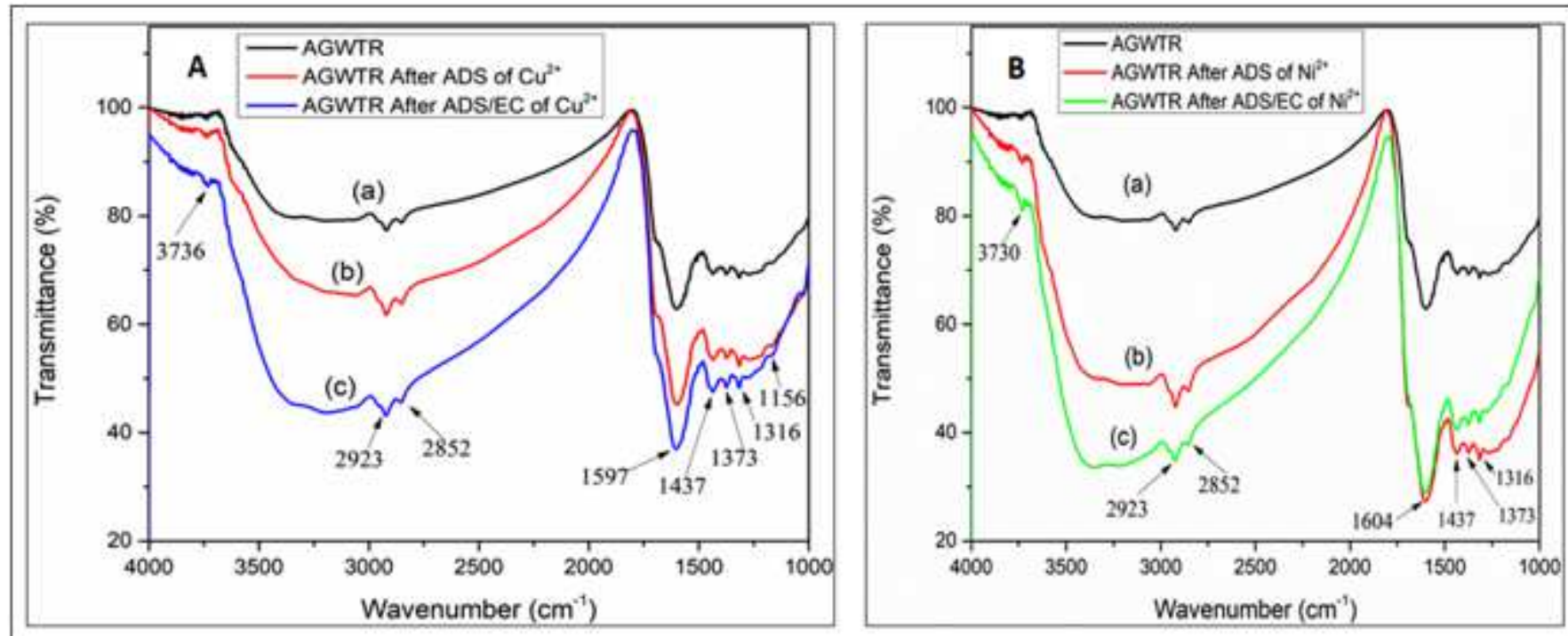

Figure 3

FT-IR spectroscopy characterization of activated green waste tea: A(a) AGWTR before adsorption, (b) AGWTR after adsorption of Cu2+ and (c) AGWTR after ADS/EC of Cu2+. B (a) AGWTR before adsorption, (b) AGWTR after adsorption of Ni2+ and (c) AGWTR after ADS/EC of Cu2+. B (a) AGWTR before adsorption, (b) AGWTR after adsorption of Ni2+ and (c) AGWTR after ADS/EC of Ni2+.
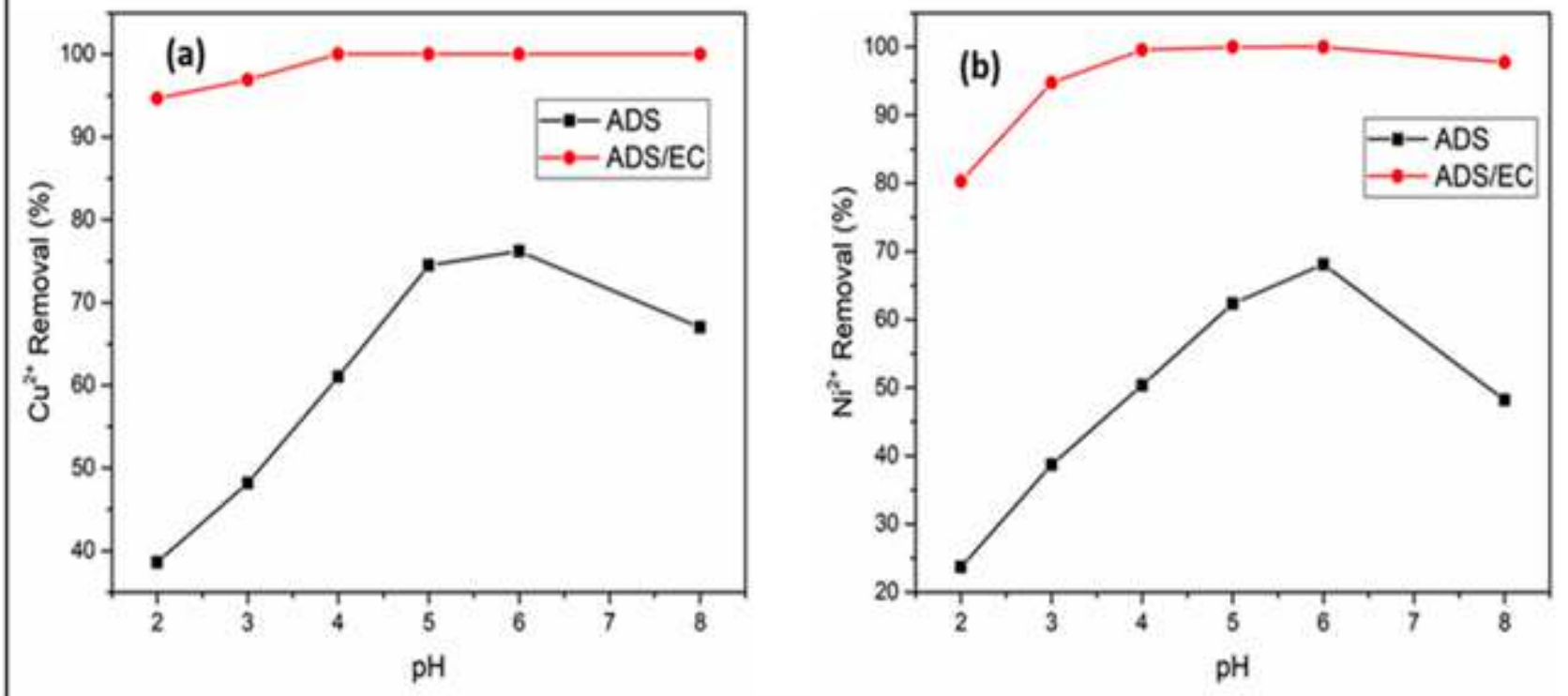

Figure 4

Effect of $\mathrm{pH}$ on (a) Cu2+ and (b) Ni2+ removal of the synthesized wastewater during the ADS and ADS/EC coupling processes (AGWTR dose $=1 \mathrm{~g} \cdot \mathrm{L}-1$, Initial conc. $=20 \mathrm{mg} \cdot \mathrm{L}-1$ and Current density $=1.19$ $\mathrm{mA} / \mathrm{cm} 2)$. 

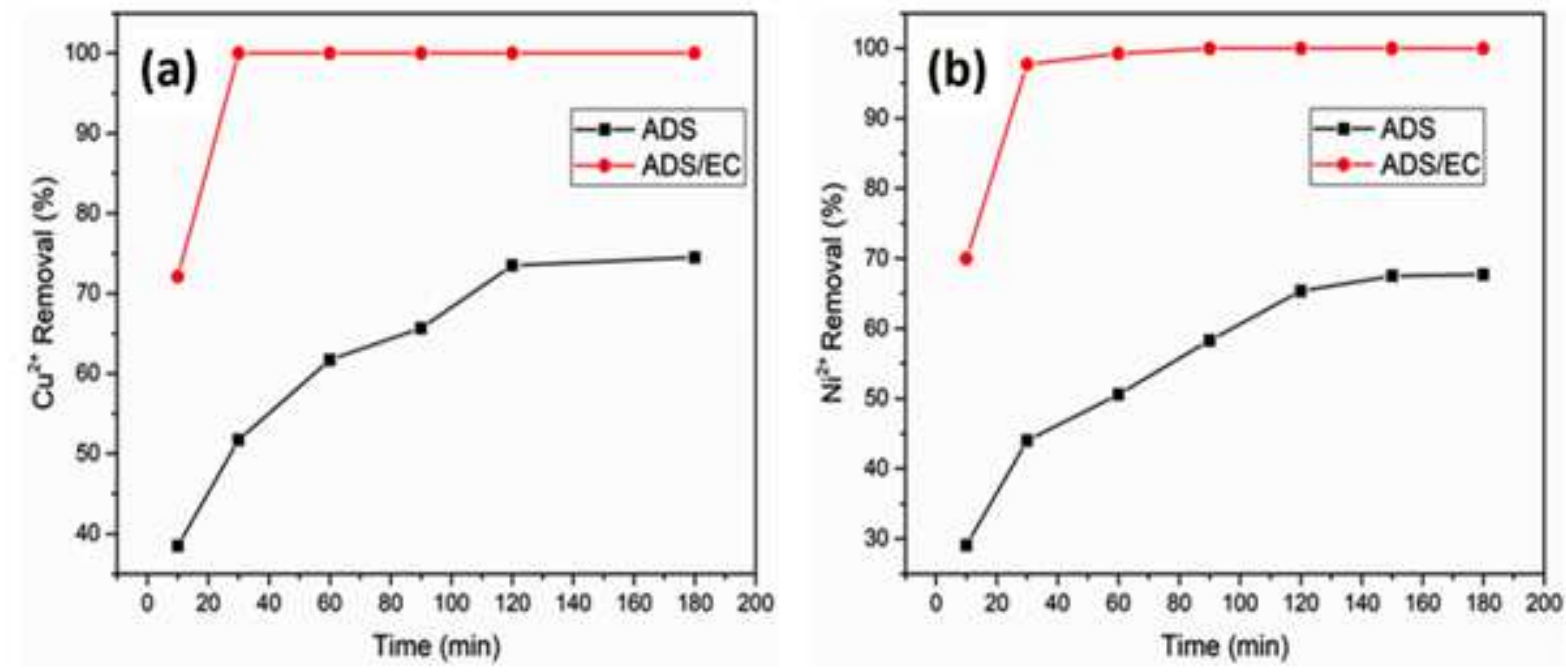

Figure 5

Effect of time on (a) Cu2+ and (b) Ni2+ removal synthesized wastewater during the ADS and ADS/EC coupling processes (Activated green waste tea dose $=1 \mathrm{~g} . \mathrm{L}-1$, Initial conc. $=20 \mathrm{mg} . \mathrm{L}-1$ and Current density $=1.19 \mathrm{~mA} / \mathrm{cm} 2)$.
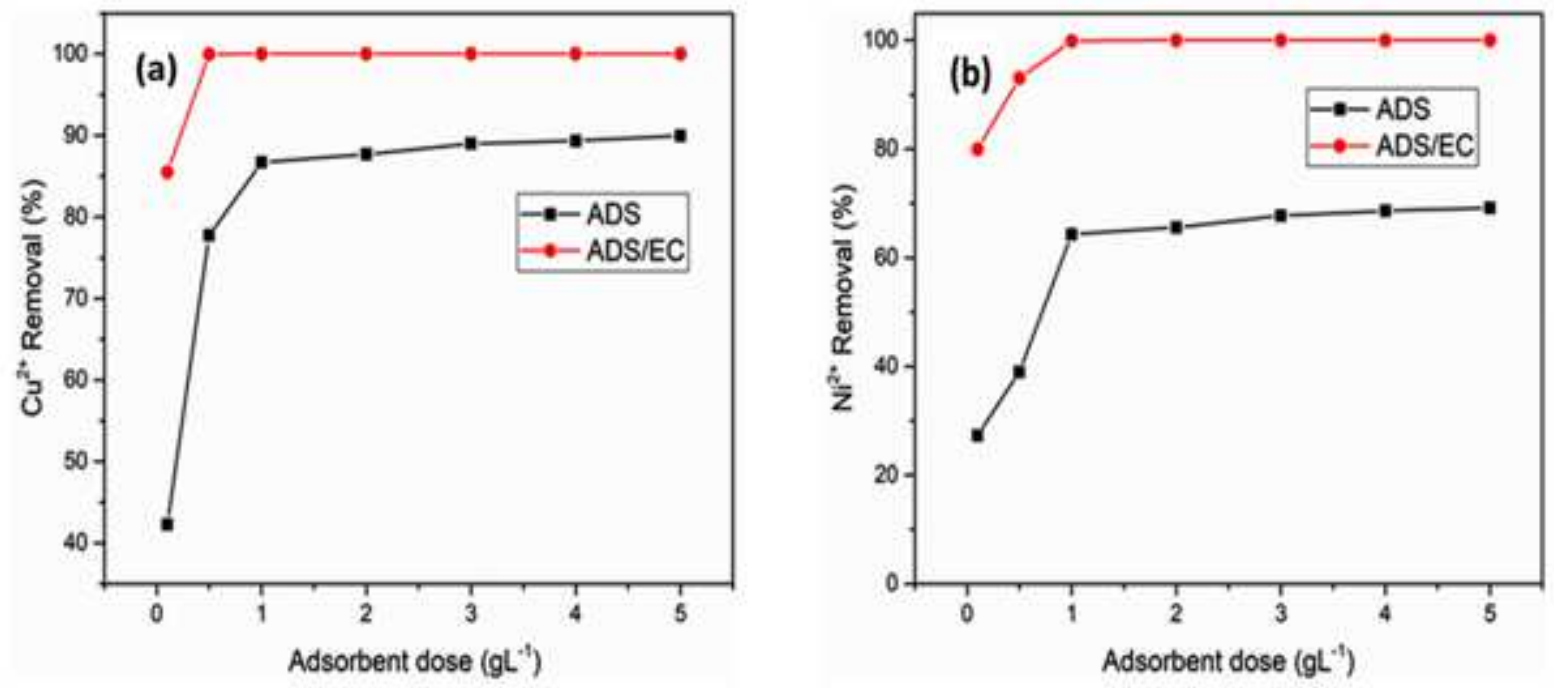

Figure 6

Effect of Adsorbent dose on (a) Cu2+ and (b) Ni2+ removal of the synthesized wastewater during the ADS and ADS/EC coupling processes (Initial conc. $=20 \mathrm{mg} \cdot \mathrm{L}-1$ and Current density $=1.19 \mathrm{~mA} / \mathrm{cm} 2$ ). 


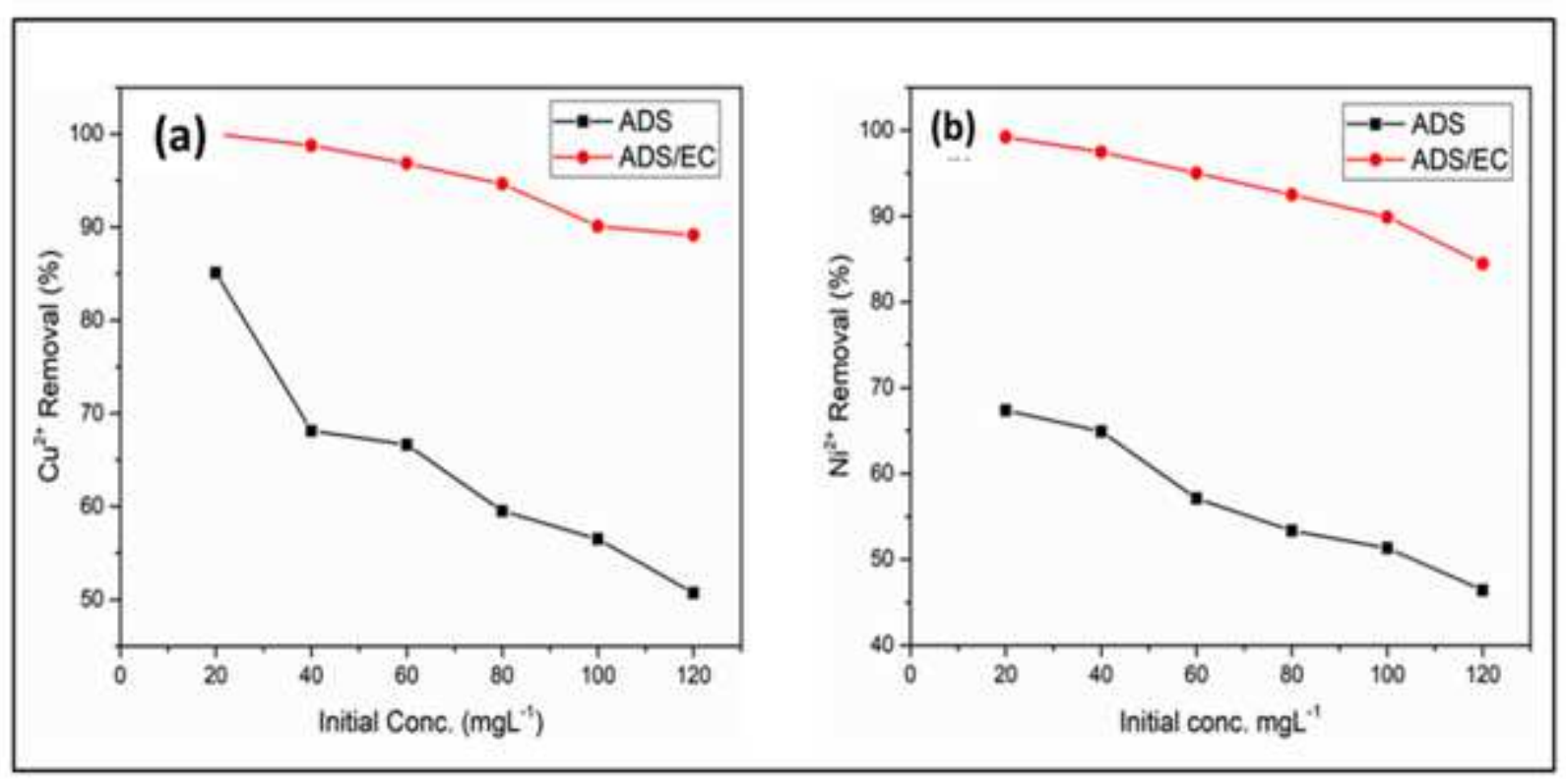

\section{Figure 7}

Effect of Initial Concentration on (a) $\mathrm{Cu} 2+$ and (b) Ni2+ removal of the synthesized wastewater during the ADS and ADS/EC coupling processes (AGWTR= $1 \mathrm{~g} \cdot \mathrm{L}-1$ and Current density $=1.19 \mathrm{~mA} / \mathrm{cm} 2$ ).

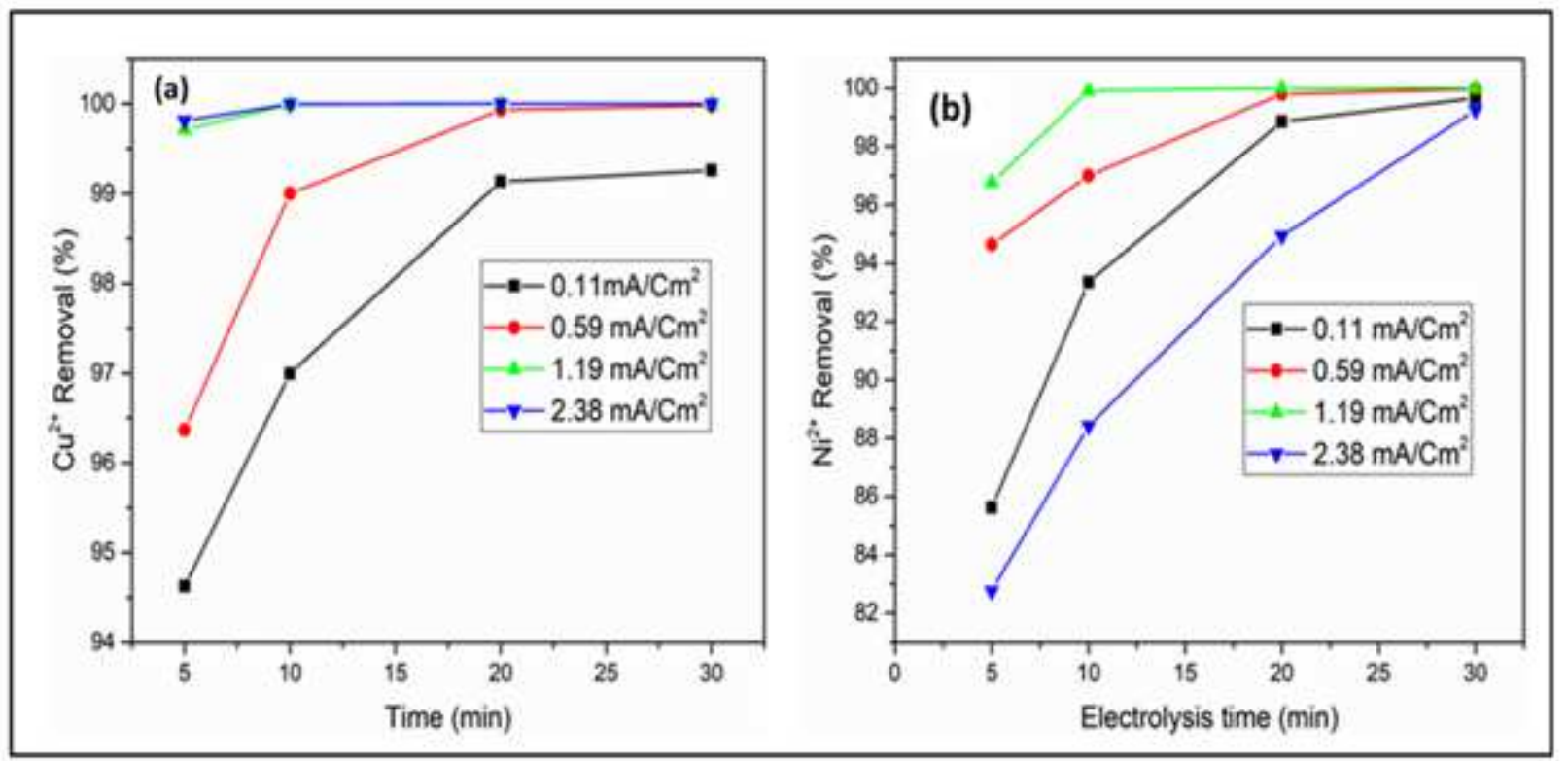

Figure 8

Effect of Current density on (a) Cu2+ and (b) Ni2+ removal of the synthesized wastewater during the ADS and $\mathrm{ADS} / \mathrm{EC}$ coupling processes (Activated green tea waste dose $=1 \mathrm{~g} \cdot \mathrm{L}-1, \mathrm{pH}=6$, Current density $=1.19$ $\mathrm{mA} / \mathrm{cm} 2$, Initial conc. $=20 \mathrm{mg} \cdot \mathrm{L}-1$ and contact time $=120 \mathrm{~min})$. 

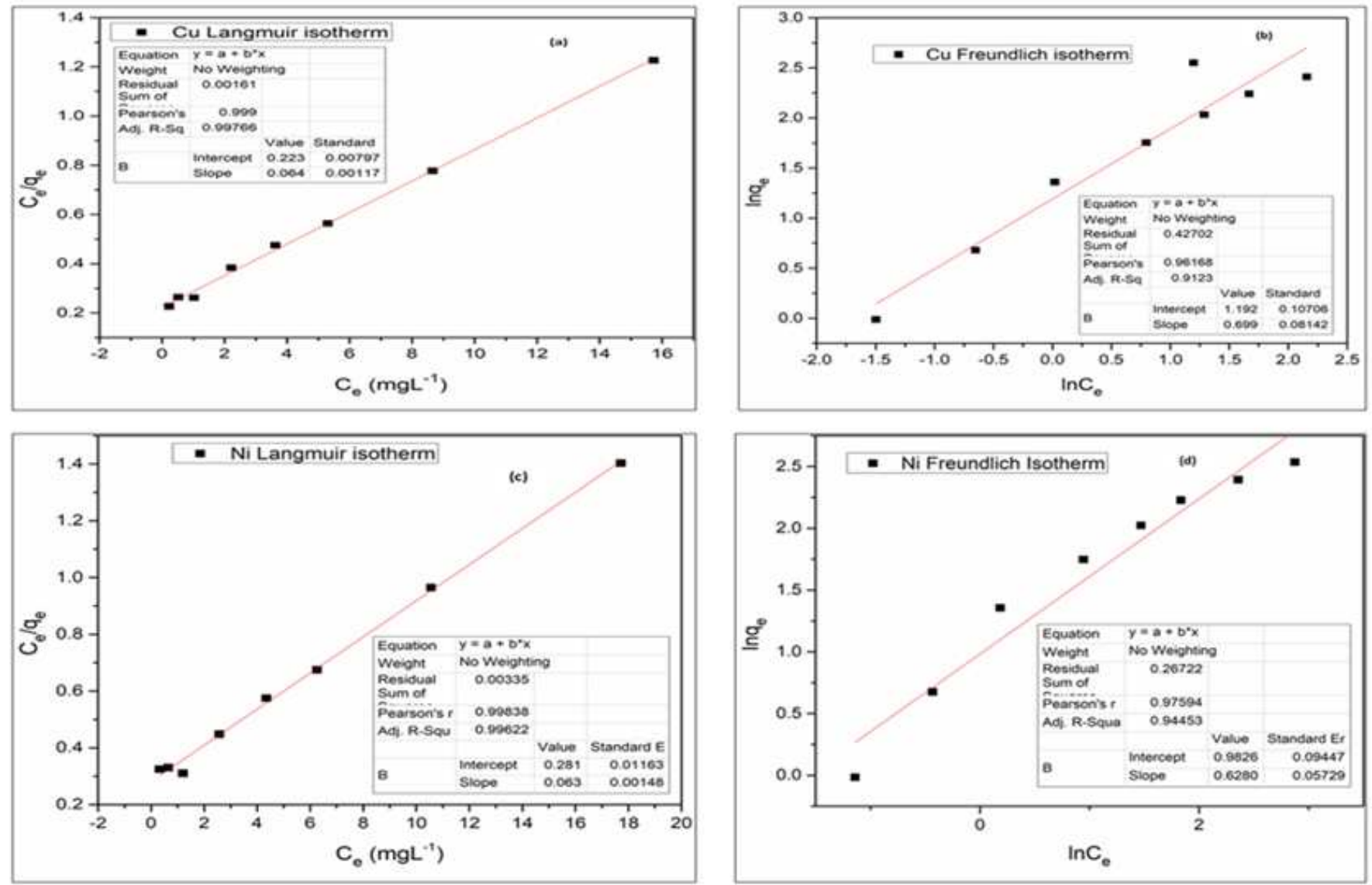

Figure 9

Adsorption/electrocoagulation isotherms: (a) Langmuir isotherm for $\mathrm{Cu} 2+$, (b) Freundlich isotherm for $\mathrm{Cu} 2+$, Langmuir isotherm for $\mathrm{Ni2}+$ and Freundlich isotherm for $\mathrm{Ni2}+$. 

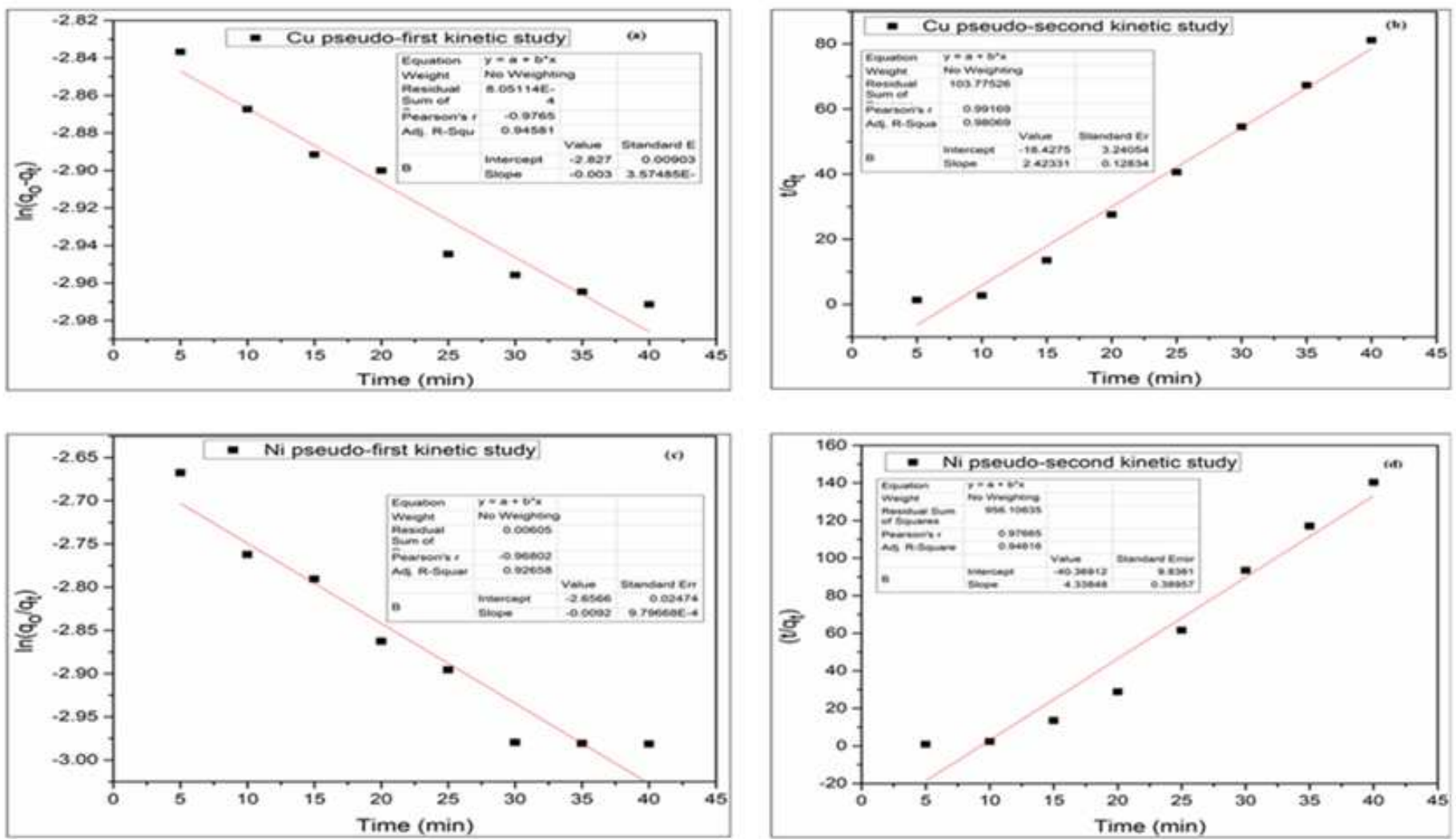

Figure 10

Adsorption/electrocoagulation Kinetic study (a) pseudo-first kinetic for Cu2+, (b) pseudo-second kinetic for $\mathrm{Cu} 2+$, (c) pseudo-first kinetic for $\mathrm{Ni2}+$ and (d) pseudo-second kinetic for $\mathrm{Ni2}+$. 


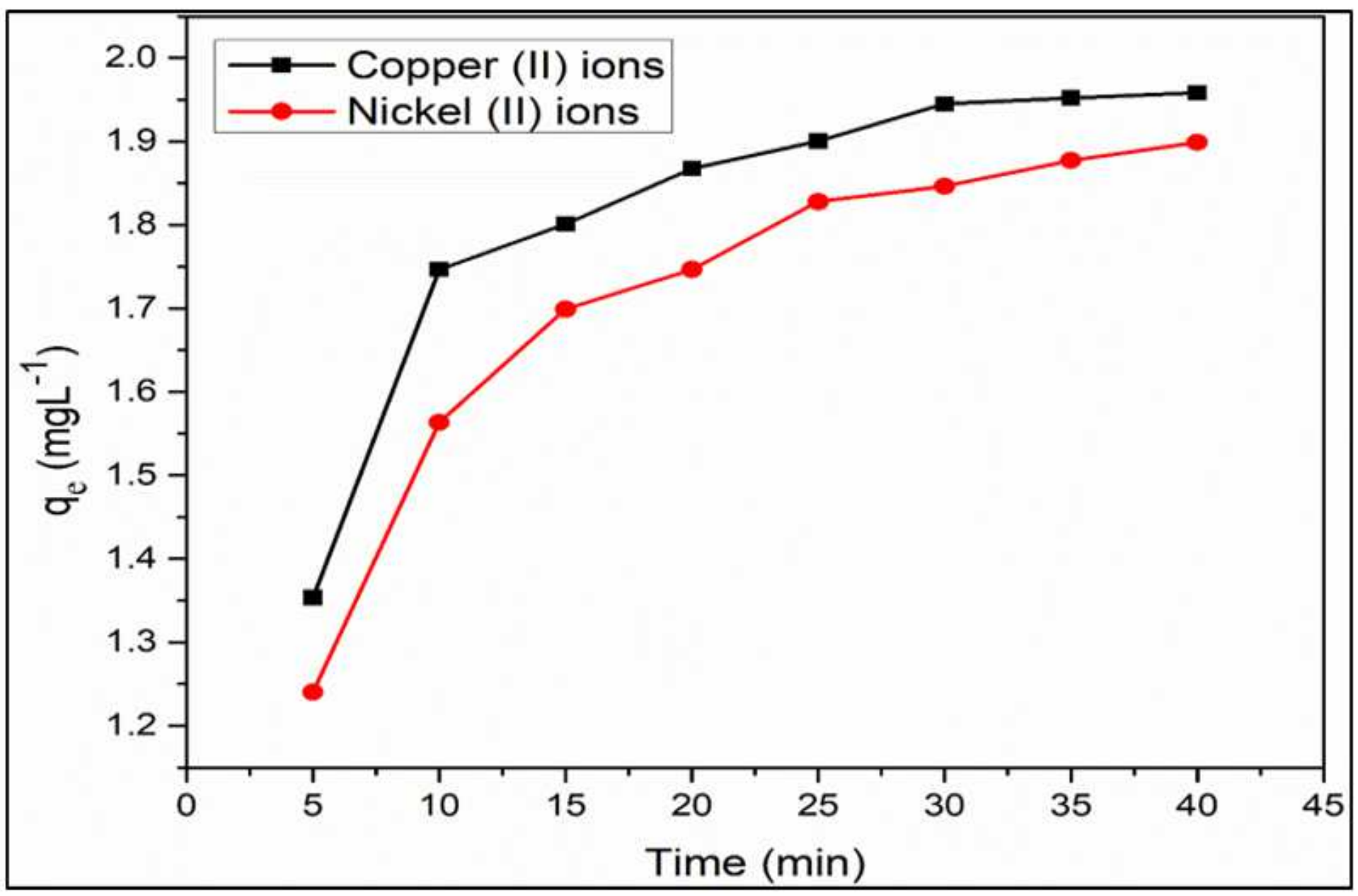

Figure 11

Combination of $\mathrm{Cu} 2+$ and $\mathrm{Ni} 2+$ ions in solution with $20 \mathrm{mg} \cdot \mathrm{L}-1$ at $\mathrm{T}=30^{\circ} \mathrm{C}$ 


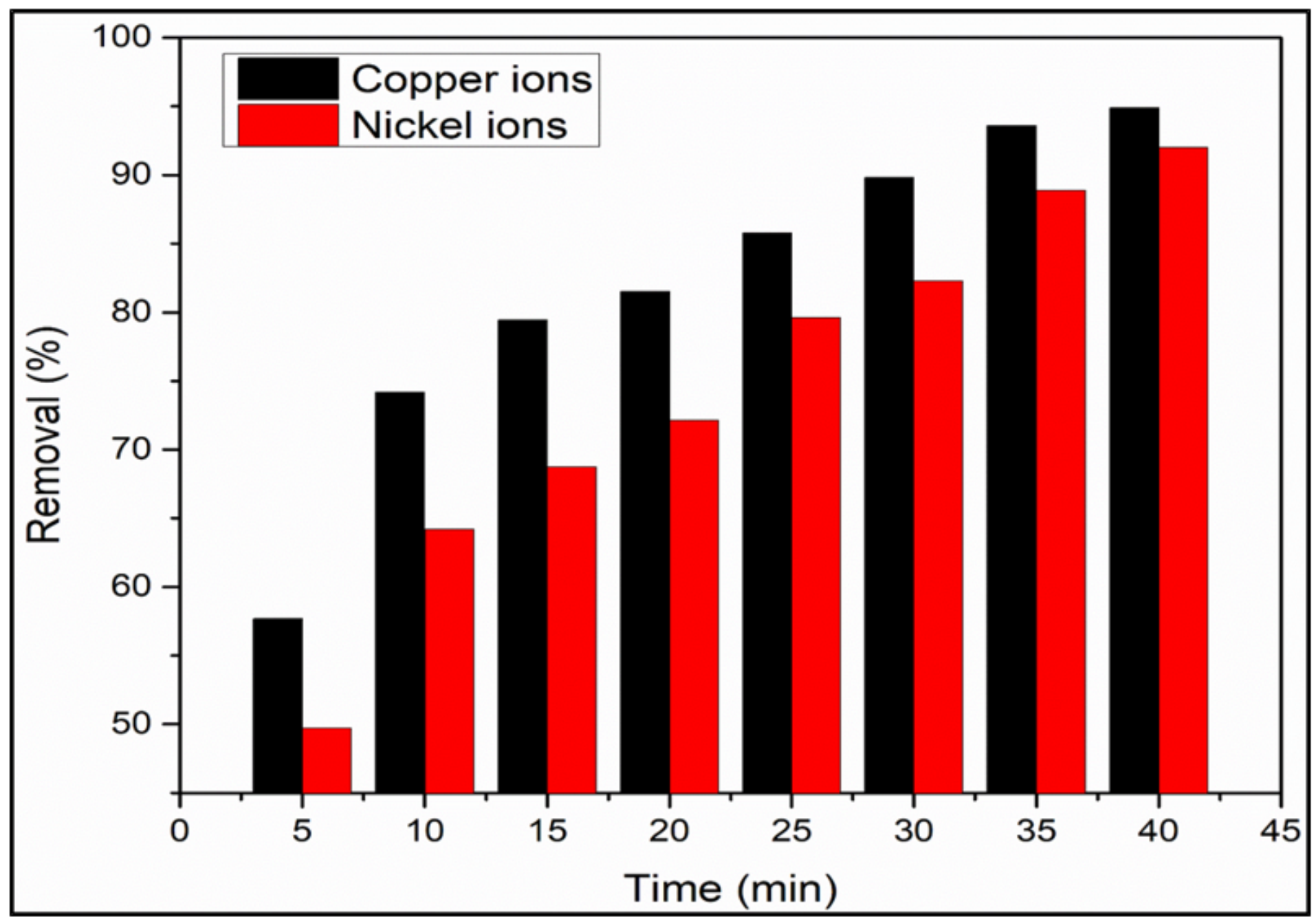

Figure 12

Maximum removal efficiency with reuse of the generated AGWTR for $\mathrm{Cu} 2+$ and $\mathrm{Ni2}+$ removal using ADS/EC process. (AGWTR $=1 \mathrm{~g} ; \mathrm{Cu} 2+$ and $\mathrm{Ni} 2+=20 \mathrm{mg} \cdot \mathrm{L}-1$ at $\mathrm{T}=30^{\circ} \mathrm{C}$ ).

\section{Supplementary Files}

This is a list of supplementary files associated with this preprint. Click to download.

- Table2.docx 